\title{
Duplex surface treatment of steels by nitriding and chromizing
}

\author{
A. Pramanik*1, F. Hakami ${ }^{1}$, A. K. Basak ${ }^{2}$ \\ ${ }^{1}$ Department of Mechanical Engineering, Curtin University, Bentley, Australia \\ ${ }^{2}$ Adelaide Microscopy, the University of Adelaide, Australia
}

\begin{abstract}
Duplex surface treatment, that is, chromizing and plasma nitriding of steels have attracted interest from industrial sectors because of its attractive properties and ability to apply on different types of steels. This paper aims to investigate duplex treatment on different types of steels at different treatment conditions. The improvements of the treated surfaces in terms of morphology and thickness, composition, surface hardness and roughness, as well as wear and friction of the engineered layer on AISI 1045, AISI 1020, AISI 1020, H13, ASTM A213, AISI 52100 and AISI 8620 alloys have been analysed. It was found that several layers of different thickness are formed due to duplex treatment which depends on the carbon content of specimen and temperature of the treatment. Mainly carbides and nitrides of chromium and iron are formed which the amount and composition of them are controlled by duplex treatment process parameters. These compounds enhance the hardness and wear resistance of the treated surface. The $\mathrm{Cr}_{\mathrm{x}} \mathrm{N}$ phase is the main contributor towards high microhardness of duplex treated layers. In addition to high hardness, it also provides excellent wear resistance properties. The plasma nitriding process reduces the coefficient of friction of chromized steels due to the lower friction coefficient of chromium nitride. However, the surface roughness of the treated surface increases due to the intrinsic properties of formed phases.
\end{abstract}

Keywords: Duplex treatment, Chromizing, Plasma nitriding, Steels

*Corresponding author

Email: alokesh.pramanik@ curtin.edu.au,

Phone: +61 89266 7981, Fax: +61 892662681

\section{Introduction}

The requirements to increase the service life of machine components have prompted the development of various surface treatment techniques and their combination. There are many researches on developing protective coatings for engineering steels with excellent tribological 
properties. In the early days, hard coatings such as $\mathrm{TiN}$ and $\mathrm{TiC}$ were widely deposited on machine components and tools. Later, many other coatings have also been used, such as AlN, TiAlN and chromium nitrides, like $\mathrm{CrN}$ and $\mathrm{Cr}_{2} \mathrm{~N}$ (Baggio-Scheid, De Vasconcelos et al. 2003). It has been seen that components subjected to such treatments have improved surface properties that are different from the bulk base material though the improved surface layer and such layers becomes an integral part of the base material (Shetty, Kumar et al. 2009). The surface improvement is an established knowledge and significantly affects technology, economy and environment due to low capital investment, high profitability, design changes and technical innovation. There are many advances in the field of surface engineering such as optimization of traditional processes (e.g. electro- and electro less plating, weld surfacing, thermal spraying and thermo chemical treatments); commercialization of the modern techniques (e.g. CVD, PVD, plasma thermo-chemical processes, plasma spraying and ion implantation); developments of innovative hybrid technologies (e.g. plasma immersion ion implantation, and plasma source ion implantation); emergence of new coating materials (e.g. diamond and diamond-like coatings). The great achievements have been made in the above mentioned first generation surface engineering. There are also trend to use the sequential application of two (or more) established surface technologies to produce a surface composite with combined properties, which are unobtainable through any individual surface technology. This type of application is called duplex surface engineering or second generation surface engineering (Bell, Dong et al. 1998). According to the interactions between the two individual processes and their relative contributions to the combined effects of the composite layer, duplex surface engineering may fall into two general groups. In the first group, two individual processes complement each other and the combined effects result from both processes. In the second group, one process supplements and reinforces the other and the resultant properties are mainly related to one process. Chromizing and then nitrided steel is a typical example of the first group while electron beam surface melting of a sprayed overlay is a typical example of the second group (Bell, Dong et al. 1998). The proper combinations of the first generation techniques can produce lots of duplex surface engineering methods. This is reflected very clearly in the literature, such as chromium pack diffusion and plasma nitriding (Chang, Lee et al. 1999, Taktak, Gunes et al. 2008, Hakami, Sohi et al. 2011, Zeng, Yang et al. 2012), plasma nitriding and plasma assisted PVD TiN coating (Van Stappen, Kerkhofs et al. 1993, Ma, Li et al. 2001, Panjan, Urankar et al. 2002, Novák, Vojtěch et al. 2006, Qi, Leng et al. 2007, De Las Heras, Egidi et al. 2008), plasma nitriding and aluminizing (Haftlang, Habibolahzadeh et al. 2014), coated by $\mathrm{Cr}, \mathrm{Al}$, or $\mathrm{Ni}$, and 
subsequently annealed in a furnace and finally irradiated by a high-current electron beam (Pogrebnjak and Shumakova 1999), pack cementation chromizing and boronizing (Lee, Kim et al. 2004), plasma nitriding and post-oxidation (Mahboubi and Fattah 2005), nitriding treatment followed by carbon treatment (Mouri, Mabille et al. 2001) and many more. The variation in the surface/duplex methods can also be introduced by changing the sequence of the processes such as chromizing of nitrided specimen (Hakami, Sohi et al. 2011) and nitriding of chromized specimen (Hakami, Sohi et al. 2011).

In recent years, duplex treatment of chromizing and plasma nitriding have attracted interest (Baggio-Scheid, De Vasconcelos et al. 2003, Taktak, Gunes et al. 2008). This has given the possibility of using mild steels in applications that were previously restricted to tool steels. Thus much research focus has been given on the duplex treatment of chromizing and plasma nitriding compare to other duplex treatment. The chromizing is widely used as surface coating technology which is applied economically to improve the performance of components and develop high wear resistant layer on metal or alloy substrates. Chromizing is done by thermoreactive deposition/diffusion process (TRD) which is a method of incorporating $\mathrm{Cr}$ in the surface of the steels which eventually form a hard, wear-resistant layer of carbides, nitrides, or carbonitrides on the metal surface upon thickness of tens of micrometers. In this process, the carbon and nitrogen in the steel react with $\mathrm{Cr}$ and form a layer with a carbide-forming or nitride-forming element such as vanadium, niobium, tantalum, chromium, molybdenum, or tungsten, which is dense and metallurgically bonded carbide or nitride coating at the substrate surface. with high wear, corrosion and oxidation resistance make it possible to form multi component and composite layers with high service characteristics (Taktak, Ulker et al. 2008). Various chromizing processes have been developed, such as solid method (pack-cementation method), liquid method (molten-salt technique), and gas method (Wang, Lu et al. 2005, Cao, WU et al. 2007). Chromized layer consisted of various chromium carbides such as $\mathrm{Cr}_{23} \mathrm{C}_{6}, \mathrm{Cr}_{7} \mathrm{C}_{3}$ and $\mathrm{Cr}_{3} \mathrm{C}_{2}$ in TRD chromizing process (AraI and Harper 1991).

Nitriding processes proved to be an important surface treatment since the beginning of the last century (Zagonel, Figueroa et al. 2006) where the nitrogen is introduced into the surface of steel with the assistance of plasma which offers a great flexibility to tailor desired chemical and structural surface properties of the bulk properties. It provides the modified surface without dimensional change and distortion of the component. Ion nitriding provides better control on chemistry and uniformity (Shetty, Kumar et al. 2009). Several plasma 
techniques are developed to satisfy different industrial demands where fine nitriding control is required. All these techniques improve the mechanical and tribological properties of the surface due to precipitation of fine nitrides in the diffusion zone (Zagonel, Figueroa et al. 2006, Hubbard, Partridge et al. 2010). This improvements contribute to better wear resistance, fatigue strength, surface hardness and corrosion resistance and as well as support a subsequent coating of industrial components (Ahangarani, Mahboubi et al. 2006). The plasma nitriding is becoming increasingly popular because of environmentally cleanliness (Hubbard, Partridge et al. 2010). Recently, in the field of plasma diffusion and deposition processes for surface treatment of materials, some technical solutions provided the step ahead towards the industrial applications (Zlatanović 2003).

It is possible to combine these two above mentioned processes (a) change the chemical and phase composition of the layers easily and effectively (b) reduce the number of defects such as porosity and (c) increase the strength of their adhesion with the substrate during duplex diffusion treatments. In many tribological applications, hard coatings of metal nitrides are now commonly in use (Taktak, Gunes et al. 2008, Taktak, Ulker et al. 2008) .

This paper investigates duplex surface treatment via plasma nitriding of pack chromized samples and its effect on layer's thickness, composition, hardness, and wear resistance. In addition, effect of other parameters, such as temperature, composition, and gas mixture are investigated.

\section{Scope of this paper}

It is interesting to note that the research on duplex treatment by plasma nitriding of pack chromized samples has been performed on different samples and processing conditions. The information on this treatment is not well organized and a clear picture is not available about the improvements of the surface layer. It is also important to know the best processing condition as well as the alloying elements in the iron alloy which favours the improved treated surface layer. Thus, this study scientifically investigates duplex treatment by plasma nitriding and chromizing based on the available literature and answers some critical questions as mentioned above. The tables 1, 2, 3 and 4 show samples, composition, pack chromizing and plasma nitriding conditions, respectively based on the literature. This study will mainly focus on the researches mentioned in the tables 1, 3 and 4, and a clear understanding on this duplex treatment will be presented in terms of morphology and thickness, composition, surface hardness and roughness, and wear and friction of engineered layer. 
Table 1 Samples that are used for duplex treatment

\begin{tabular}{|c|c|c|c|c|}
\hline Researcher & $\begin{array}{c}\text { (Hakami, Sohi } \\
\text { et al. 2011) }\end{array}$ & $\begin{array}{c}\text { (Baggio-Scheid, De } \\
\text { Vasconcelos et al. 2003) }\end{array}$ & $\begin{array}{c}\text { (Chang, Lee et } \\
\text { al. 1999) }\end{array}$ & $\begin{array}{c}\text { (Taktak, Ulker } \\
\text { et al. 2008) }\end{array}$ \\
\hline Sample & AISI 1045 & AISI 1020 & $\begin{array}{c}\text { AISI 1020, H13, } \\
\text { ASTM A213 }\end{array}$ & $\begin{array}{c}\text { AISI 52100 } \\
\text { and AISI8620 }\end{array}$ \\
\hline
\end{tabular}

Table 2 Composition of materials (http://www.azom.com/article.aspx?ArticleID=6754)

\begin{tabular}{|c|c|c|c|c|c|c|c|c|c|c|c|}
\hline & $\mathrm{C}$ & $\mathrm{Fe}$ & $\mathrm{Mn}$ & $\mathrm{P}$ & $\mathrm{S}$ & $\mathrm{Cr}$ & $\mathrm{Mo}$ & $\mathrm{Si}$ & $\mathrm{V}$ & $\mathrm{Ni}$ & $\mathrm{Cu}$ \\
\hline AISI & $0.4-$ & $98.5-$ & $0.6-$ & $\leq 0.04$ & $\leq 0.05$ & - & - & - & - & - & - \\
1045 & 0.5 & 98.98 & 0.9 & & & & & & & & \\
\hline AISI & $0.17-$ & $99.08-$ & $0.3-$ & $\leq 0.04$ & $\leq 0.05$ & - & - & - & - & - & - \\
1020 & 0.23 & 99.53 & 0.6 & & & & & & & & \\
\hline H13 & $0.32-$ & $88.79-$ & $0.2-$ & 0.03 & 0.03 & $5.75-$ & $1.10-$ & $0.8-$ & $0.8-$ & 0.3 & 0.25 \\
& 0.45 & 91.42 & 0.5 & & & 5.50 & 1.75 & 1.2 & 1.2 & & \\
\hline ASTM & $0.1-$ & $97.38-$ & $0.30-$ & 0.025 & 0.025 & $0.50-$ & $0.44-$ & $0.1-$ & - & - & - \\
A213 & 0.2 & 98.51 & 0.61 & & & 0.81 & 0.65 & 0.3 & & & \\
\hline AISI & $0.98-$ & $96.5-$ & $0.25-$ & $\leq$ & $\leq$ & $1.3-$ & & 0.15 & - & - & - \\
52100 & 1.1 & 97.32 & 0.45 & 0.025 & 0.025 & 1.60 & & -0.3 & & & \\
\hline AISI & $0.18-$ & $96.89-$ & $0.7-$ & $\leq$ & $\leq$ & $0.4-$ & $0.15-$ & $0.15-$ & & $0.4-$ & - \\
8620 & 0.23 & 98.02 & 0.9 & 0.035 & 0.04 & 0.6 & 0.25 & 0.35 & & 0.7 & \\
\hline
\end{tabular}

Table 3 Conditions of pack chromizing

\begin{tabular}{|c|c|c|c|c|}
\hline Researcher & Sample & $\begin{array}{c}\text { Temp } \\
\left({ }^{\circ} \mathrm{C}\right)\end{array}$ & $\begin{array}{c}\text { Time } \\
(\mathrm{h})\end{array}$ & $\begin{array}{c}\text { Powder mixture } \\
(\text { wt. } \%)\end{array}$ \\
\hline $\begin{array}{c}\text { (Hakami, Sohi et al. } \\
2011)\end{array}$ & AISI 1045 & 1000 & 5 & $\begin{array}{c}25 \% \mathrm{Cr}, 69 \% \mathrm{Al}_{2} \mathrm{O}_{3}, 6 \% \\
\mathrm{NH}_{4} \mathrm{Cl}\end{array}$ \\
\hline $\begin{array}{c}\text { (Baggio-Scheid, De } \\
\text { Vasconcelos et al. 2003) }\end{array}$ & AISI 1020 & $\begin{array}{c}800- \\
1300\end{array}$ & 5 & $\begin{array}{l}25 \% \mathrm{Cr}, 69 \% \mathrm{Al}_{2} \mathrm{O}_{3}, 6 \% \\
\mathrm{NH}_{4} \mathrm{Cl}\end{array}$ \\
\hline
\end{tabular}




\begin{tabular}{|c|c|c|c|c|}
\hline $\begin{array}{c}\text { (Chang, Lee et al. 1999) } \\
\text { AISI 1020, }\end{array}$ & $\begin{array}{c}1200- \\
1300\end{array}$ & 5 & $\begin{array}{c}25 \% \mathrm{Cr}, 69 \% \mathrm{Al}_{2} \mathrm{O}_{3}, 6 \% \\
\mathrm{NH}_{4} \mathrm{Cl}\end{array}$ \\
\hline $\begin{array}{c}\text { (Taktak, Ulker et al. } \\
2008)\end{array}$ & AISI 52100 & 1000 & 5 & $\begin{array}{c}40 \% \mathrm{Cr}, 45 \% \mathrm{Al}_{2} \mathrm{O}_{3}, 15 \% \\
\mathrm{NH}_{4} \mathrm{Cl}\end{array}$ \\
\hline $\begin{array}{c}\text { (Taktak, Gunes et al. } \\
2008)\end{array}$ & AISI 52100 & 1000 & 5 & $\begin{array}{c}40 \% \mathrm{Cr}, 45 \% \mathrm{Al}_{2} \mathrm{O}_{3}, 15 \% \\
\mathrm{NH}_{4} \mathrm{Cl}\end{array}$ \\
\hline
\end{tabular}

Table 4 Conditions of plasma nitriding

\begin{tabular}{|c|c|c|c|c|}
\hline Researcher & Sample & Temp $\left({ }^{\circ} \mathrm{C}\right)$ & Time (h) & Gas mixture \\
\hline $\begin{array}{c}\text { (Hakami, Sohi et al. 2011) } \\
\text { (Baggio-Scheid, De } \\
\text { Vasconcelos et al. 2003) }\end{array}$ & AISI 1020 & $530-550$ & 5 & $75 \% \mathrm{~N}_{2}+25 \% \mathrm{H}_{2}$ \\
\hline (Chang, Lee et al. 1999) & AISI 1020, & 530 & 1 & $75 \% \mathrm{~N}_{2}+25 \% \mathrm{H}_{2}$ \\
\hline H13 & AISI 52100 & 500 & 5 & $50 \% \mathrm{~N}_{2}-50 \% \mathrm{H}_{2}$ \\
\hline $\begin{array}{c}\text { (Taktak, Ulker et al. 2008) } \\
\text { 2008) }\end{array}$ & AISI 52100 & 500 & 5 & $\begin{array}{c}50 \% \mathrm{~N}_{2}-50 \% \mathrm{H}_{2} \\
50 \% \mathrm{~N}_{2}+50 \% \mathrm{H}_{2} \text { and } \\
75 \% \mathrm{~N}_{2}+25 \% \mathrm{H}_{2}\end{array}$ \\
\hline
\end{tabular}

\section{Morphology and thickness}

Fig. 1 illustrates cross-sectional micrographs of the AISI 1045 steel samples, which are chromized and post plasma nitrided at different temperatures (Hakami, Sohi et al. 2011). It shows that the thickness of the chromized layer is $8 \pm 1 \mu \mathrm{m}$ (Fig. 1a). Fig. 2 demonstrates the $\mathrm{X}$-ray line of $\mathrm{Cr}$ in the chromized sample, achieved by EDS analysis that shows high amount of chromium in the upper region and lower amount of it in the lower area of the diffused layer. It was considered that after nitriding the surface layer thickness increases to approximately $12 \pm 1 \mu \mathrm{m}$ at low nitriding temperature of $530{ }^{\circ} \mathrm{C}$ (Fig. $1 \mathrm{~b}$ ) and $10 \pm 2 \mu \mathrm{m}$ at higher nitriding temperature of $550{ }^{\circ} \mathrm{C}$ (Fig. 1c). By increasing of nitriding temperature, the surface layer's thickness decreases, which is mainly due to increase of ion energy in sputtering and partial removal of chromized layer on the surface. Increase of treatment 
temperature results in increase of the applied voltage, which successively enhances the kinetic energy of the incident ions (or atoms) (Heydarzadeh Sohi 2010). The formed layers seem to be quite compact. A single surface layer is observed for the chromized specimen that is shown in Fig. 1a. Figs. 1b and 1c demonstrate that after post nitriding, the thickness of the duplex treated layers has increased and two distinct layers are seen at the surfaces (Hakami, Sohi et al. 2011).
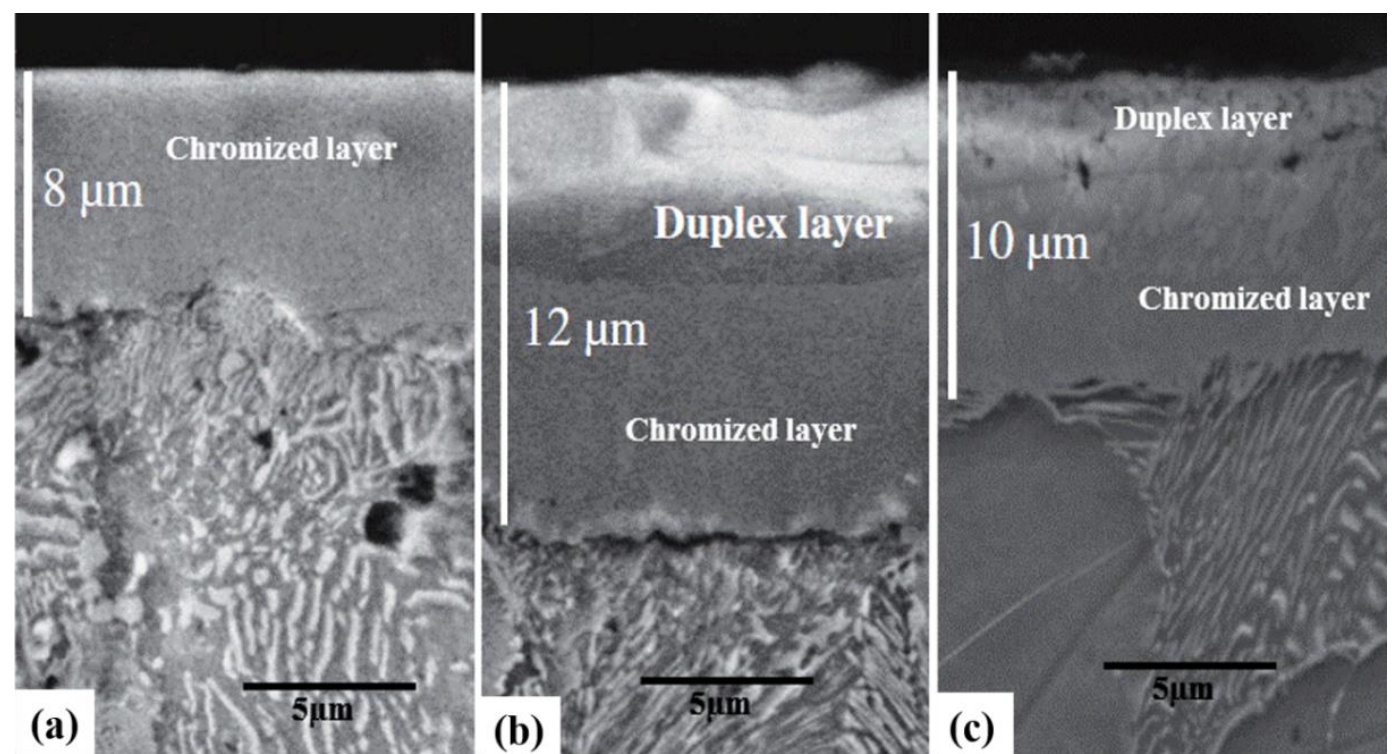

Fig. 1 SEM micrograph of the AISI 1045 steel after chromizing (a), and chromizing and post nitriding at $530{ }^{\circ} \mathrm{C}(\mathrm{b})$, and $550{ }^{\circ} \mathrm{C}$ (c) (Hakami, Sohi et al. 2011).

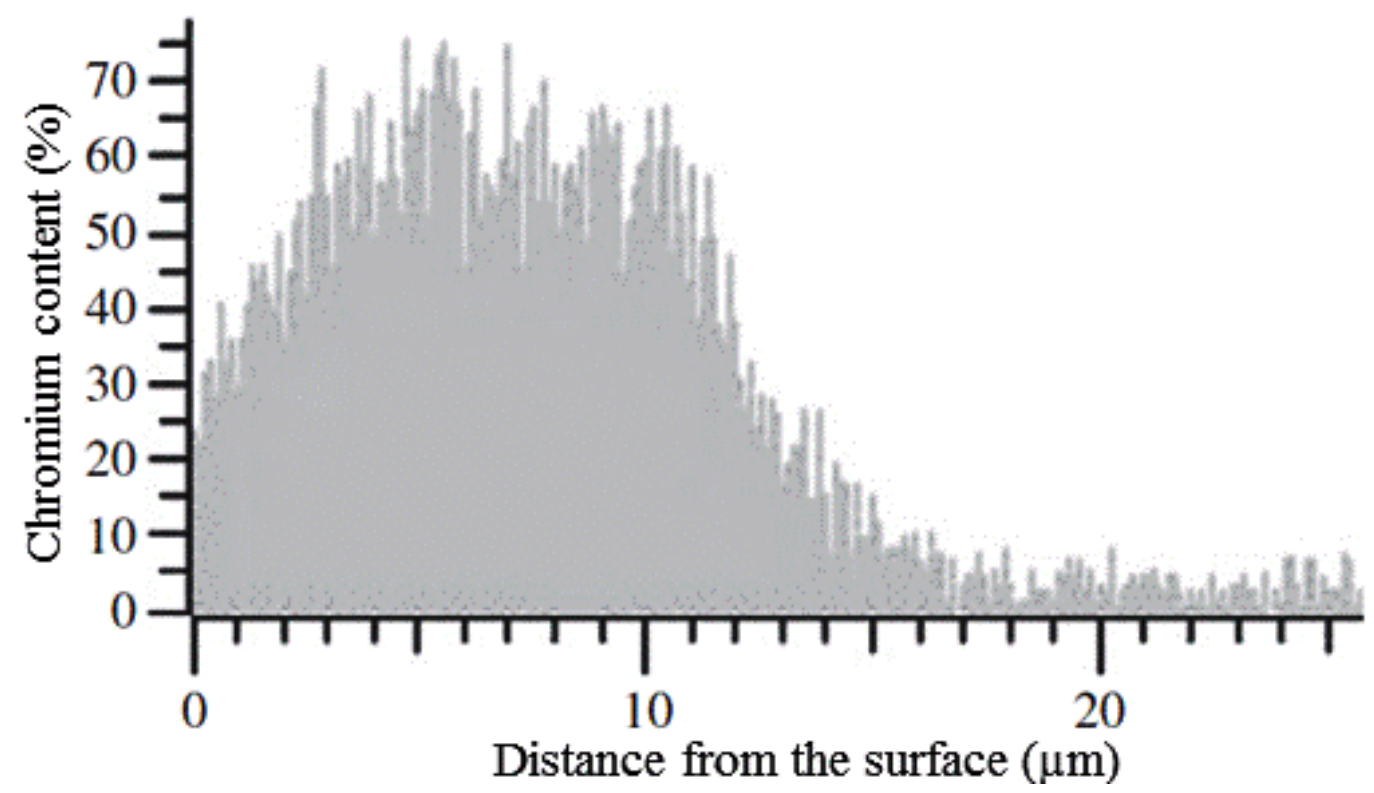

Fig. 2 X-ray line for Cr in chromized AISI 1045 steel as shown in Fig. 1a (Hakami, Sohi et al. 2011) 
Fig. 3 shows cross-sectioned micrographs of the AISI 1020 steel samples after chromizing. Baggio-Scheid et al. reported that the chromized layer for temperatures up to $900{ }^{\circ} \mathrm{C}$ is very superficial and thickness is lower than $3 \mu \mathrm{m}$, which is obvious in Fig. 3a. The layer thickness increases, with increasing temperature growing to approximately up to $8 \mu \mathrm{m}$ at a temperature of $1100{ }^{\circ} \mathrm{C}$. A diffusion layer (a dark band) is formed, approximately $4 \mu \mathrm{m}$ below the white layer, as shown in Fig. 3b. With increasing temperature to $1300{ }^{\circ} \mathrm{C}$, the chromized layer thickness grows drastically, reaching to $150 \mu \mathrm{m}$. As shown in Fig. 3c, the chromized layer expands for the entire dark region below the surface. A decarburized area which is believed to be the source of carbon for carbide formation during the chromizing process, with a depth of approximately $100 \mu \mathrm{m}$ is formed between the diffuse chromized layer and the matrix (the white layer). They reported that there is no major change in the microstructure of the samples which are treated by the duplex process of chromizing and plasma nitriding up to the diffusing temperature of $1100{ }^{\circ} \mathrm{C}$. But, at $1300^{\circ} \mathrm{C}$ the interface between the chromized and the decarburized layers becomes more evident as shown in Fig. 4. The EDX line profile of $\mathrm{Cr}$ in the chromized and duplex-treated samples in Fig.4 illustrates that the diffusing $\mathrm{Cr}$ layer coincides with the dark region. The chromized samples at $1300{ }^{\circ} \mathrm{C}$ have a uniform chromium concentration of approximately $20 \mathrm{wt}$. \% Cr, near to the decarburized layer, which decreases suddenly. The thickness of the duplex layer (white layer on top of the diffusion layer) was between 20 and $30 \mu \mathrm{m}$ (Baggio-Scheid, De Vasconcelos et al. 2003).

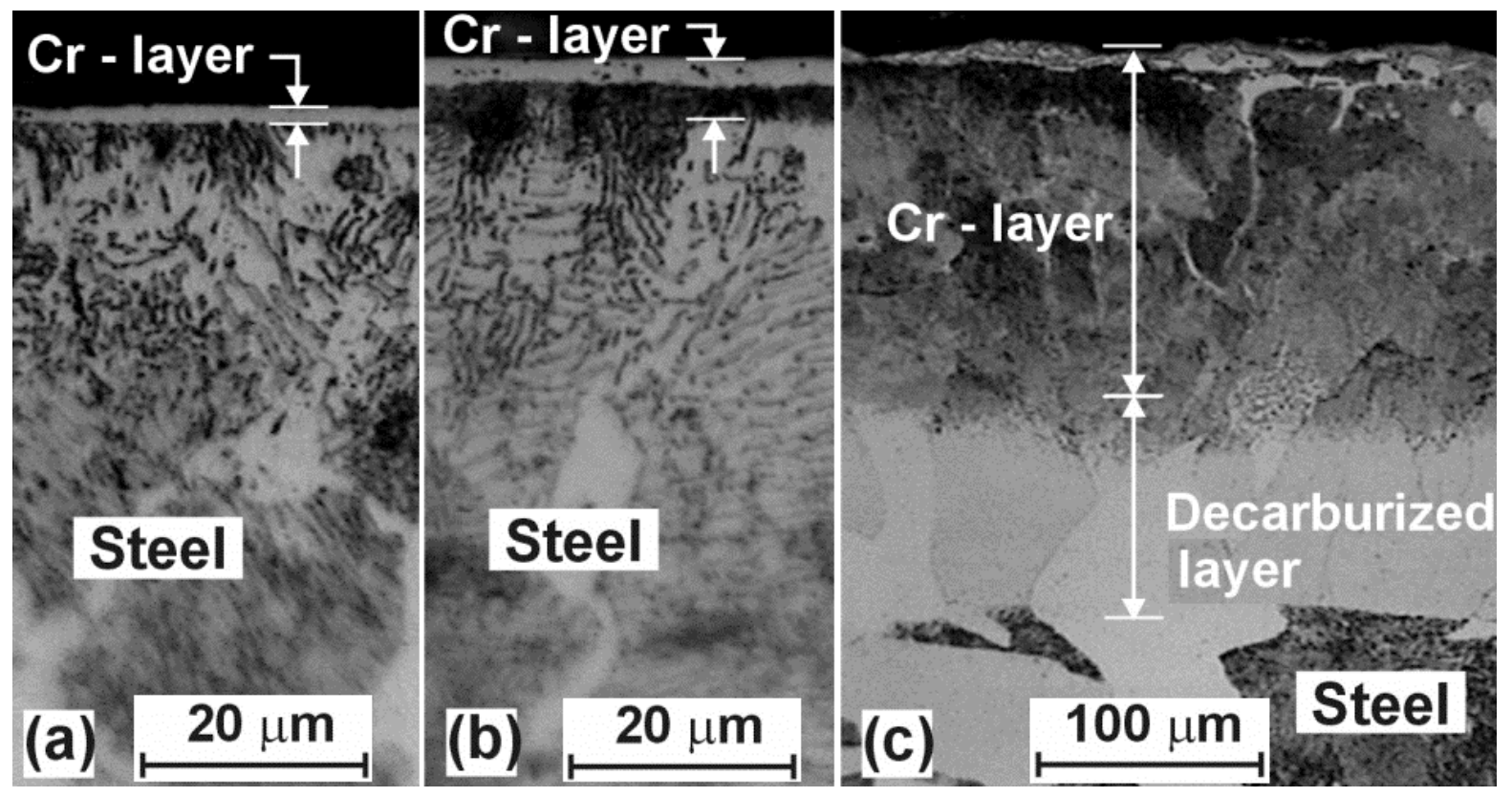

Fig. 3 Cross sectional optical micrographs of AISI 1020 steel samples chromized for 5 hours at (a) $900{ }^{\circ} \mathrm{C}$,(b) $1100{ }^{\circ} \mathrm{C}$ and(c) $1300{ }^{\circ} \mathrm{C}$ (Baggio-Scheid, De Vasconcelos et al. 2003). 


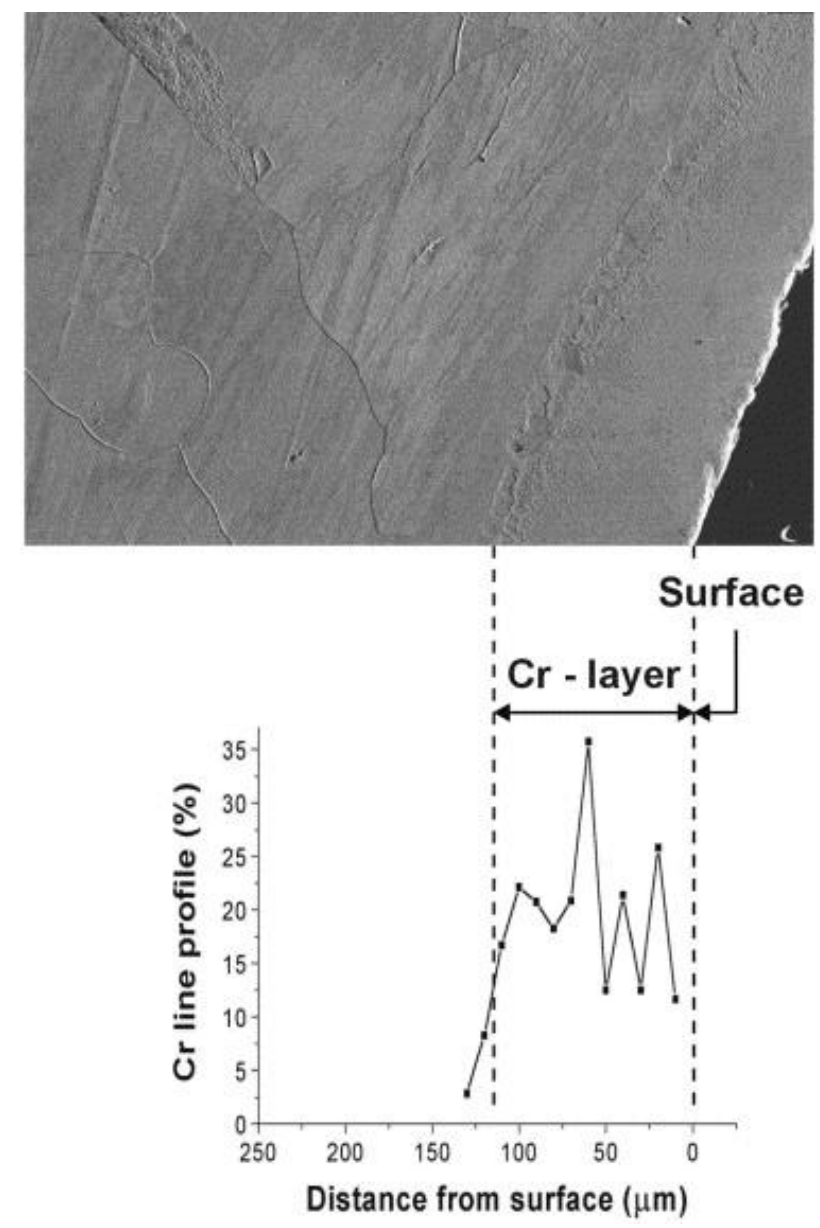

Fig. 4 Cross-sectional micrograph and line profile of Cr in AISI 1020 steel treated by the duplex process of chromizing and plasma nitriding (chromizing for $5 \mathrm{~h}$ at $1300{ }^{\circ} \mathrm{C}$; plasma nitriding for $1 \mathrm{~h}$ at $450{ }^{\circ} \mathrm{C}$ in $\mathrm{H}_{2}-75 \% \mathrm{~N}_{2}$ )(Baggio-Scheid, De Vasconcelos et al. 2003).

The cross-sectional microstructure after the duplex treatment is shown in Fig. 5. It is demonstrated that after chromizing a thick and featureless chromized layer is formed in AISI 1020 steel. In addition a ferrite-pearlite microstructure is also noted in typical low carbon mild steel. The thickness of the chromized layer was 180-190 $\mu \mathrm{m}$ in this case. The formation of surface carbide as well as grain boundary carbide occurs in this case. A layer of decarburized zone between the chromized layer and the matrix (approximately $220 \mu \mathrm{m}$ thick) was observed. It was believed to be a source of carbon to form the surface as well as grain boundary carbides during chromizing. AISI H13 tool steel which has approximately 0.37 $\mathrm{wt} \% \mathrm{C}$ is expected to have large carbide formation during chromizing. After chromizing under the same processing conditions, the thickness of the chromized layer in the AISI H13 specimen was $150 \mu \mathrm{m}$ which was much less than that in the AISI 1020 steel. It is because of high amount of carbon in the matrix which results in an extensive formation of carbides that 
obstructs or slows chromium diffusion into the matrix, leading in a thin chromized layer. It can be concluded that amount of carbon in the matrix greatly affects the thickness of the chromized layer. The thickness of the chromized layer in ASTM A213 with $0.15 \mathrm{wt} \% \mathrm{C}$ was approximately of the order of 200-210 $\mathrm{m}$, slightly higher than that of AISI 1020 with approximately $0.2 \mathrm{wt} \% \mathrm{C}$ (Chang, Lee et al. 1999).

AISI 1020 steel does not contain any elements which have a strong affinity to nitrogen to form nitride (Lee, Chung et al. 1996). But a nitrogen diffused layer with thickness of 70$80 \mu \mathrm{m}$ is formed after chromizing of AISI 1020 steel. It could be because of chromium in the chromized layer which has increased the nitrogen diffusion by forming chromium nitride, which was later confirmed by XRD analysis (Fig. 11). SEM micrograph of the plasma nitrided layer on the surface of the chromized AISI 1020 specimen with a higher magnification in Fig. 5(b) confirms formation of a thin white layer, typical of plasma nitrided surface. After nitriding, the grain boundary carbide that was formed during the chromizing process seems to disappear. Fig. 6 illustrates EDS line profiles of chromized and plasma nitrided areas. It is seen that the $\mathrm{Cr}$ concentration at the surface is more than $25 \mathrm{wt} \% \mathrm{Cr}$ which decreasing continuously towards the interface between the chromized layer and the matrix. The Fig. 6 confirms the high concentration of nitrogen in the duplex-treated layer (Chang, Lee et al. 1999).
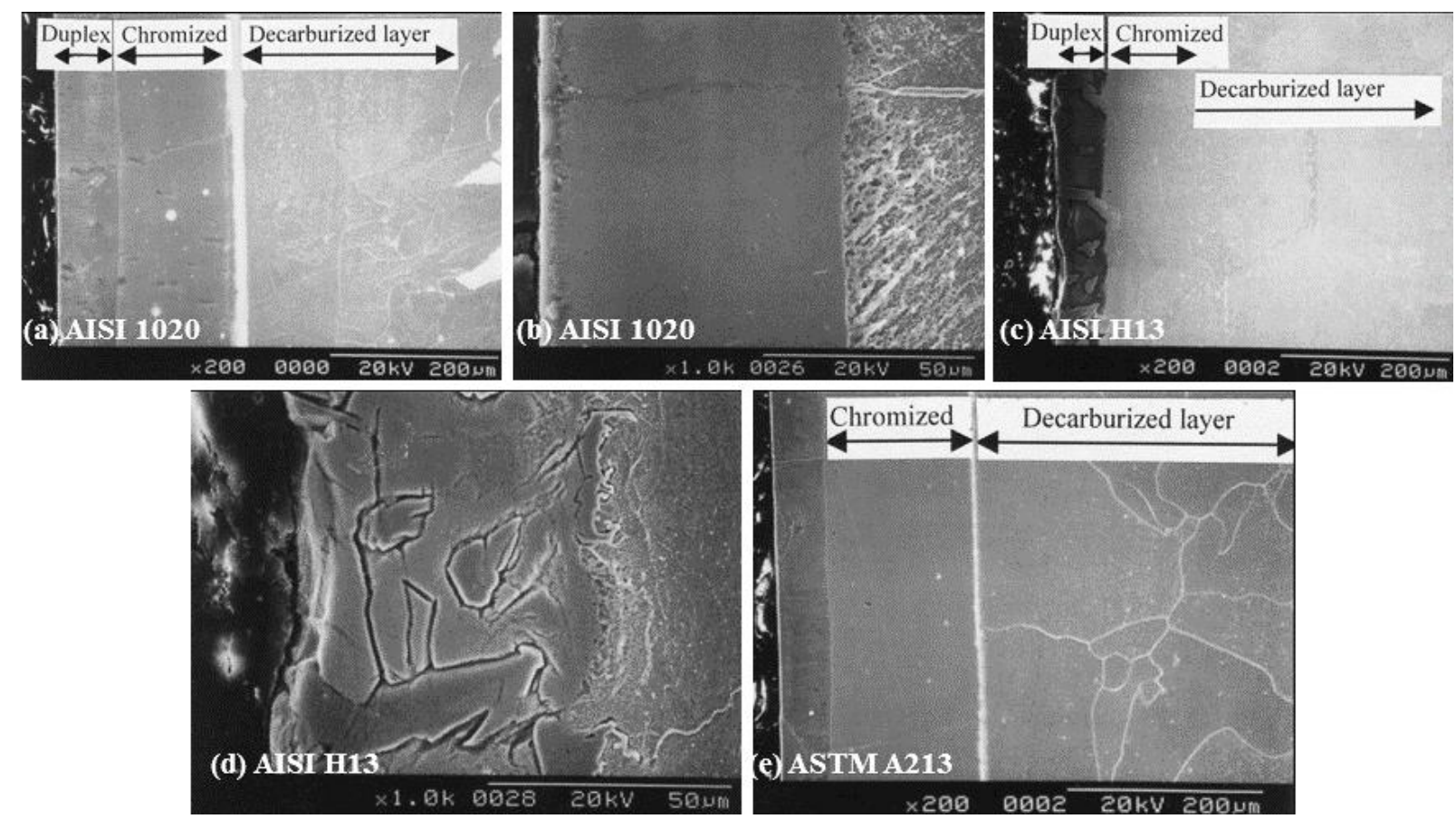

Fig. 5 Cross-sectional SEM micrographs of chromized and plasma nitrided layer of $(a, b)$ AISI 1020, (c, d) AISI H13, (e) ASTM A213 (Chang, Lee et al. 1999). 


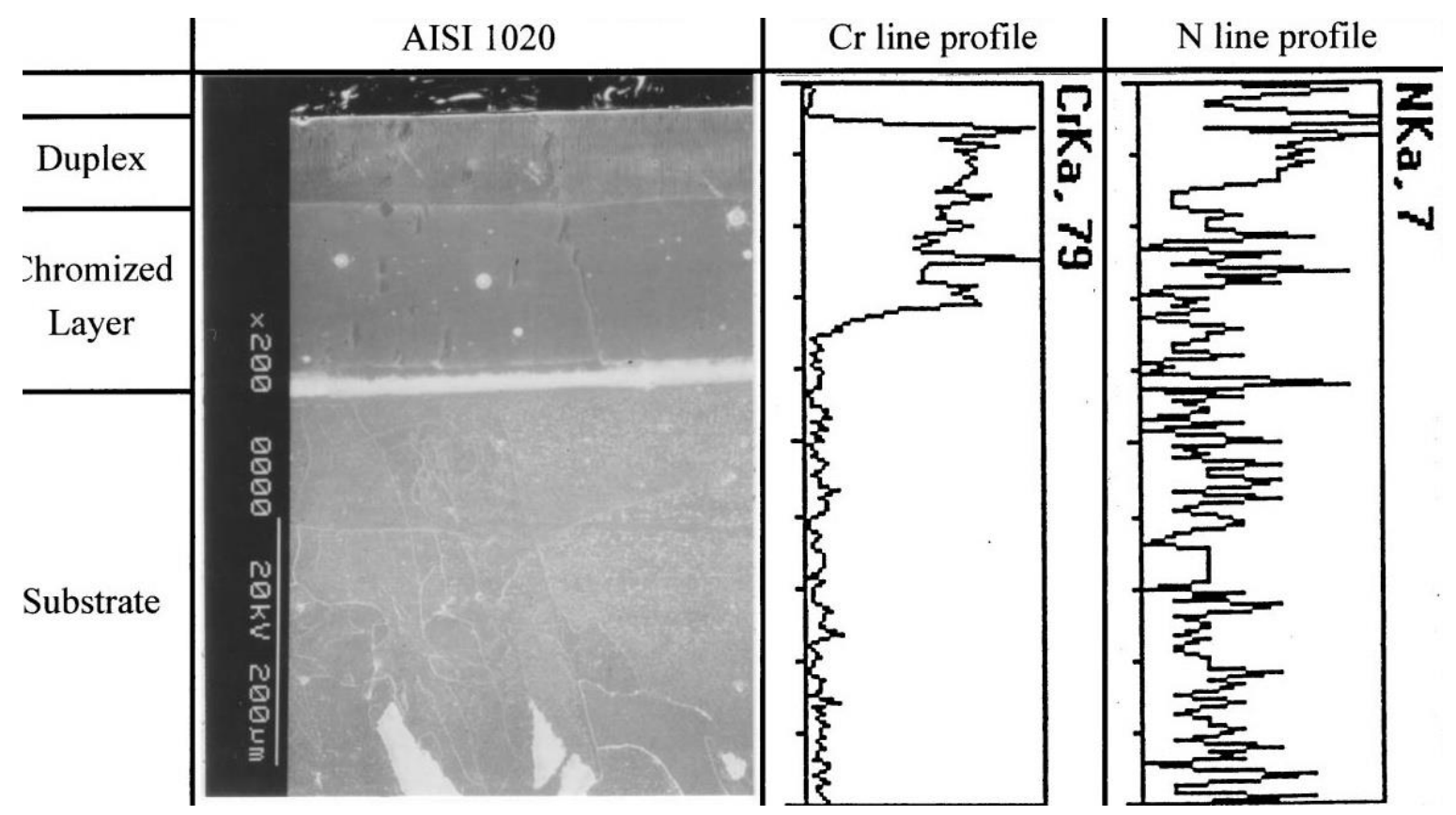

Fig.6 EDS line profiles of $\mathrm{Cr}, \mathrm{N}$ in the chromized and nitrided specimens of AISI 1020 (Chang, Lee et al. 1999).

Fig. 7 shows respectively the cross-section micrograph after chromizing and duplex treatment on AISI 52100 and 8620 steels. Fig. 7 ((a) and (b)) demonstrated a single layer for chromized steel, while two distinct layers were formed for the duplex treated steels (Fig. 7((c) and (d)). The formed Layers by chromizing and duplex treatment had relatively flat morphology. The thicknesses of the chromized layers of AISI 52100 and 8620 were $14.3 \pm 1.66 \mu \mathrm{m}$ and $10.5 \pm 1.27 \mu \mathrm{m}$. Higher percentage $(1 \mathrm{wt} \%)$ of carbon in AISI 52100 steel causes extensive formation of carbide during chromizing (Lee and Duh 2004) and the cross-sectional micrographs of this steel in Fig. 7(a) confirm this expectation. Plasma nitriding of chromized steels increased the total compound layer thickness to $17.4 \pm 1.5 \mu \mathrm{m}$ and $12.8 \pm 1.05 \mu \mathrm{m}$ values (Taktak, Ulker et al. 2008).

The effect of various gas mixture atmospheres on the cross-section micrographs after chromizing and then plasma nitriding (PN) is also shown in Fig. 7. In this case gas mixtures of $50 \% \mathrm{~N}_{2}+50 \% \mathrm{H}_{2}$ and $75 \% \mathrm{~N}_{2}+25 \% \mathrm{H}_{2}$ were considered. The coaxial grain surface structure and grain boundaries for the chromized specimen were revealed on the surface as shown in Fig. 7(a). On the other hand, plasma nitriding affected the microstructure of the samples and produced much smaller grain sizes in gas mixture of $50 \% \mathrm{~N}_{2}+50 \% \mathrm{H}_{2}$. When the amount of $\% \mathrm{~N}_{2}$ increased to $75 \%$, coarse grains appeared in the microstructure as seen in Fig. 7(c) (Taktak, Gunes et al. 2008). Table 5 indicates thickness of chromized and duplex treated (TRD+PN) layer in various plasma gas mixtures. As seen in Figs. 7(e) and (f), cracks and 
fractures occurred at the outermost layers of the samples which are duplex treated in a gas mixture of $75 \% \mathrm{~N}_{2}+25 \% \mathrm{H}_{2}$. It might be because of rubbing with emery paper during the metallographic procedure since it has brittle characteristic. A single layer and two distinct layers were formed respectively for chromized samples (Fig. 7(a-b)) and the duplex treated steels (Fig. 7(c-f)). Considering the fact that the both atoms of nitrogen substitute the carbon atoms in the chromized layer and overlay on the chromized layer, the formation of the outermost layer by plasma nitriding may be explained. It was stated that with increase of amount of Carbon, the thickness of the chromized layer enhances (Lee and Duh 2004). With increase of nitrogen content in gas mixtures during plasma nitriding of the chromized steels, the total thickness of compound layer increases.
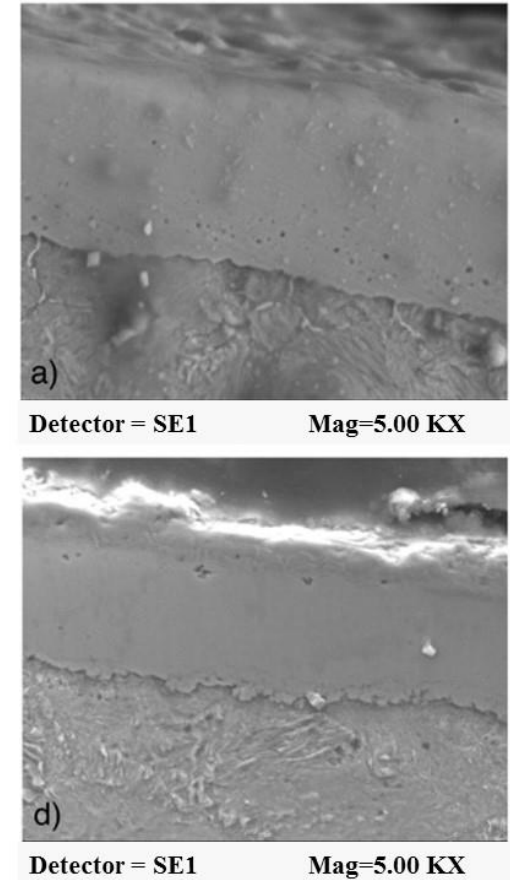

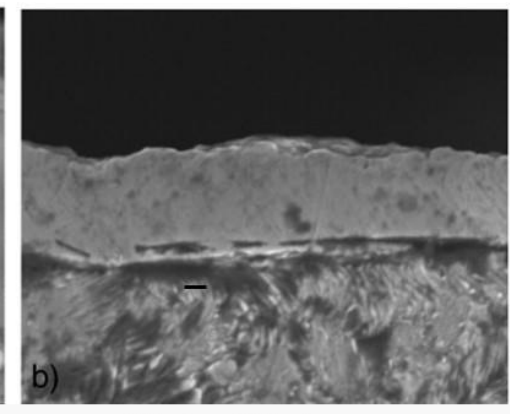

I Probe $=957 \mathrm{pA}$

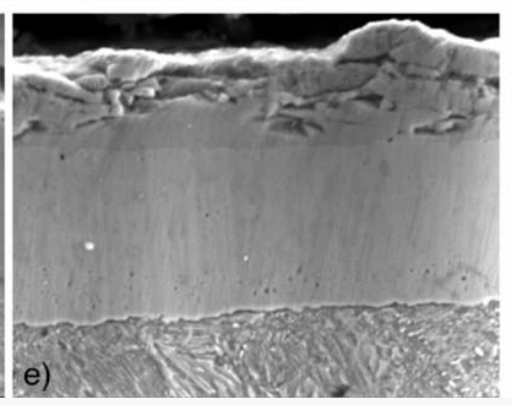

I Probe $=957$ pA
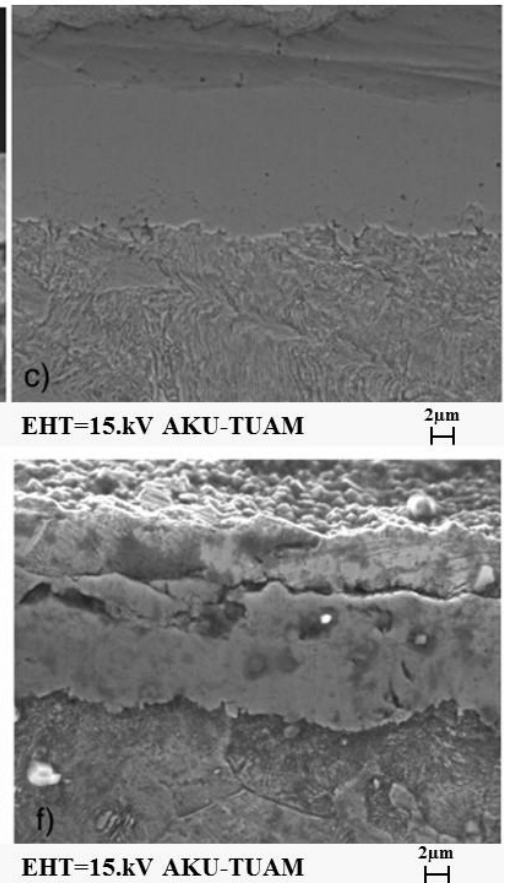

Fig. 7 Cross-sectional of chromized(a) 52100, (b) 8620 , duplex treated at $50 \% \mathrm{~N}_{2}+50 \% \mathrm{H}_{2}$ plasma; (c) 52100, (d) 8620 and duplex treated at $75 \% \mathrm{~N}_{2}+25 \% \mathrm{H}_{2}$ plasma; (e) 52100, (f) 8620 steels (Taktak, Gunes et al. 2008).

Only at the beginning of the sputtering treatment decomposition of the carbides can happen. When a nitride layer is formed, further layer growth is controlled by nitrogen diffusion. In a $100 \% \mathrm{~N}_{2}$ plasma, there is not significant change in thicknesses of duplex treated steels. Chromium nitride surface coatings were not present on these steels. It can be due to formation of strongly reducing species by hydrogen gas (Figueroa and Alvarez 2006). The hydrogen gas which is used in the gas mixture for plasma nitriding has several effects, such as (a) removal of absorbed oxygen on the surfaces (b) control of the nitrogen chemical 
potential which has effects on the growth of nitride phases and (c) increase of the nitrogen atom concentration in the plasma (Figueroa and Alvarez 2006). Besides, the NH- and Hradicals play an important role in nitriding. The existence of abundant $\mathrm{H}$ - radicals may convert the NH- radical more effectively to an active nitrogen atom on the nitride surface. In the case of nitriding in pure $\mathrm{N}_{2}$ gas, there is not any $\mathrm{NH}$ radical in the plasma (Tamaki, Tomii et al. 2000).

Table 5. Layer thickness of TRD chromized and duplex treated (TRD+PN) AISI 52100 and 8620 steels (Taktak, Gunes et al. 2008).

\begin{tabular}{|c|c|c|c|}
\hline \multirow{2}{*}{ Treatment Type } & \multirow{2}{*}{$\begin{array}{c}\text { Plasma nitriding gas } \\
\text { compositions }\end{array}$} & \multicolumn{2}{|c|}{ Layer thickness, $(\mu \mathrm{m})$} \\
\hline & & AISI 52100 & AISI 8620 \\
\hline TRD & - & $14.3 \pm 1.66$ & $10.5 \pm 1.27$ \\
\hline $\mathrm{TRD}+\mathrm{PN}$ & $25 \% \mathrm{~N}_{2}-75 \% \mathrm{H}_{2}$ & $15.4 \pm 0.78$ & $11.6 \pm 1.20$ \\
\hline $\mathrm{TRD}+\mathrm{PN}$ & $50 \% \mathrm{~N}_{2}-50 \% \mathrm{H}_{2}$ & $17.4 \pm 1.50$ & $12.8 \pm 1.05$ \\
\hline $\mathrm{TRD}+\mathrm{PN}$ & $75 \% \mathrm{~N}_{2}-25 \% \mathrm{H}_{2}$ & $19.2 \pm 1.60$ & $14.6 \pm 1.35$ \\
\hline $\mathrm{TRD}+\mathrm{PN}$ & $100 \% \mathrm{~N}_{2}$ & $14.8 \pm 0.68$ & $10.5 \pm 0.75$ \\
\hline
\end{tabular}

According to the results, duplex surface is formed in different samples after plasma nitriding of chromized layer. The layer is composed of two distinct layers (chromized layer and duplex layer) on the specimens obtained from dual treatment. Moreover, the thickness of the formed layer enhances after plasma nitriding.

\section{Composition}

The composition of chromized and duplex layers was investigated mainly by XRD analysis. XRD analysis of the chromized AISI 1045 steel surfaces presented in Fig. 8(a) shows that the surface layer contains iron, chromium as well as $\mathrm{Cr}_{2} \mathrm{C}, \mathrm{Cr}_{7} \mathrm{C}_{3}$ and $\mathrm{Fe}_{2} \mathrm{C}$. Figs. 8 (b) and (c) illustrate formation of $\mathrm{Cr}_{2} \mathrm{~N}, \mathrm{Fe}_{2} \mathrm{~N}, \mathrm{Fe}_{3} \mathrm{~N}, \mathrm{Cr}_{7} \mathrm{C}_{3}$ and $\mathrm{Fe}_{2} \mathrm{C}$ after post nitriding at $530{ }^{\circ} \mathrm{C}$ and formation of $\mathrm{CrN}, \mathrm{Fe}_{4} \mathrm{~N}, \mathrm{Cr}_{23} \mathrm{C}_{6}$ and $\mathrm{Fe}_{3} \mathrm{C}$ after post nitriding at $550{ }^{\circ} \mathrm{C}$, respectively (Ozdemir, Sen et al. 2007, Hakami, Sohi et al. 2011). Considering these XRD patterns, it could be said that the differences between two layer's composition with increasing nitriding temperature are formation of $\mathrm{CrN}$ and changes in composition of chromium and iron carbides and iron nitrides (Hakami, Sohi et al. 2011). 


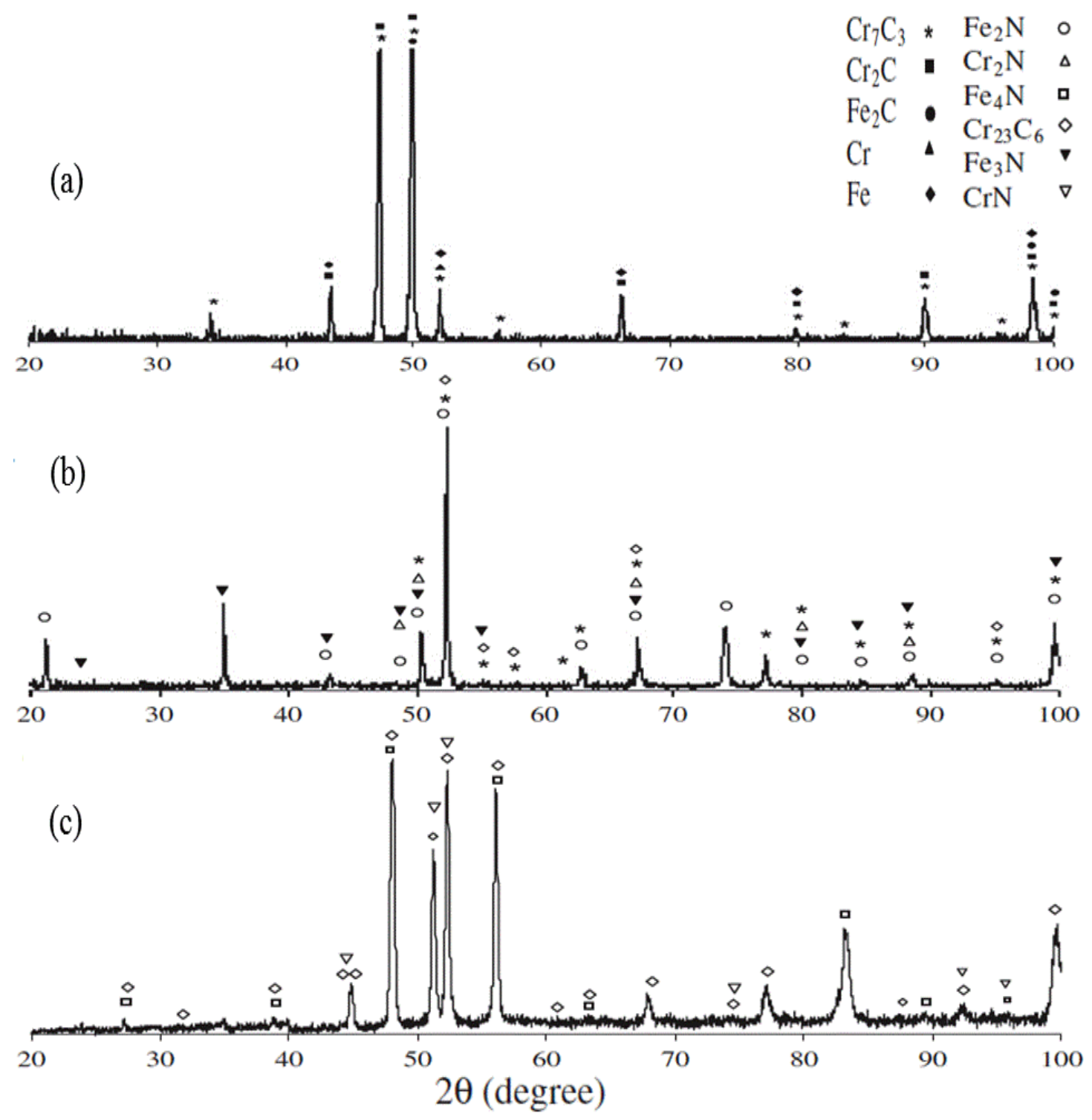

Fig. 8 XRD patterns of the AISI 1045 steel samples after chromizing (a), and post plasma nitriding at $530{ }^{\circ} \mathrm{C}(\mathrm{b})$ and $550{ }^{\circ} \mathrm{C}(\mathrm{c})($ Hakami, Sohi et al. 2011).

According to XRD analysis of the chromized AISI 1020 steel surfaces (Fig. 9(a)) metallic Cr inclusions in the $\alpha$-Fe structure, and $\mathrm{Cr}_{7} \mathrm{C}_{3}$ and $\mathrm{Fe}_{3} \mathrm{C}$ carbides are formed. The increase in the $\mathrm{Cr}_{7} \mathrm{C}_{3}$ peaks with temperature is due to the growth of the diffusing $\mathrm{Cr}$ layer, as well as increase of chromium concentration. The duplex process resulted in formation of $\mathrm{CrN}$ and $\mathrm{Cr}_{2} \mathrm{~N}$ nitrides for all the chromizing temperatures which is shown in Fig. 9(b). The $\mathrm{Cr}_{7} \mathrm{C}_{3}$ phase remains in all the samples, but the $\mathrm{Fe}_{3} \mathrm{C}$ phase could no longer be identified in the sample chromized at $1300{ }^{\circ} \mathrm{C}$ (Baggio-Scheid, De Vasconcelos et al. 2003). 


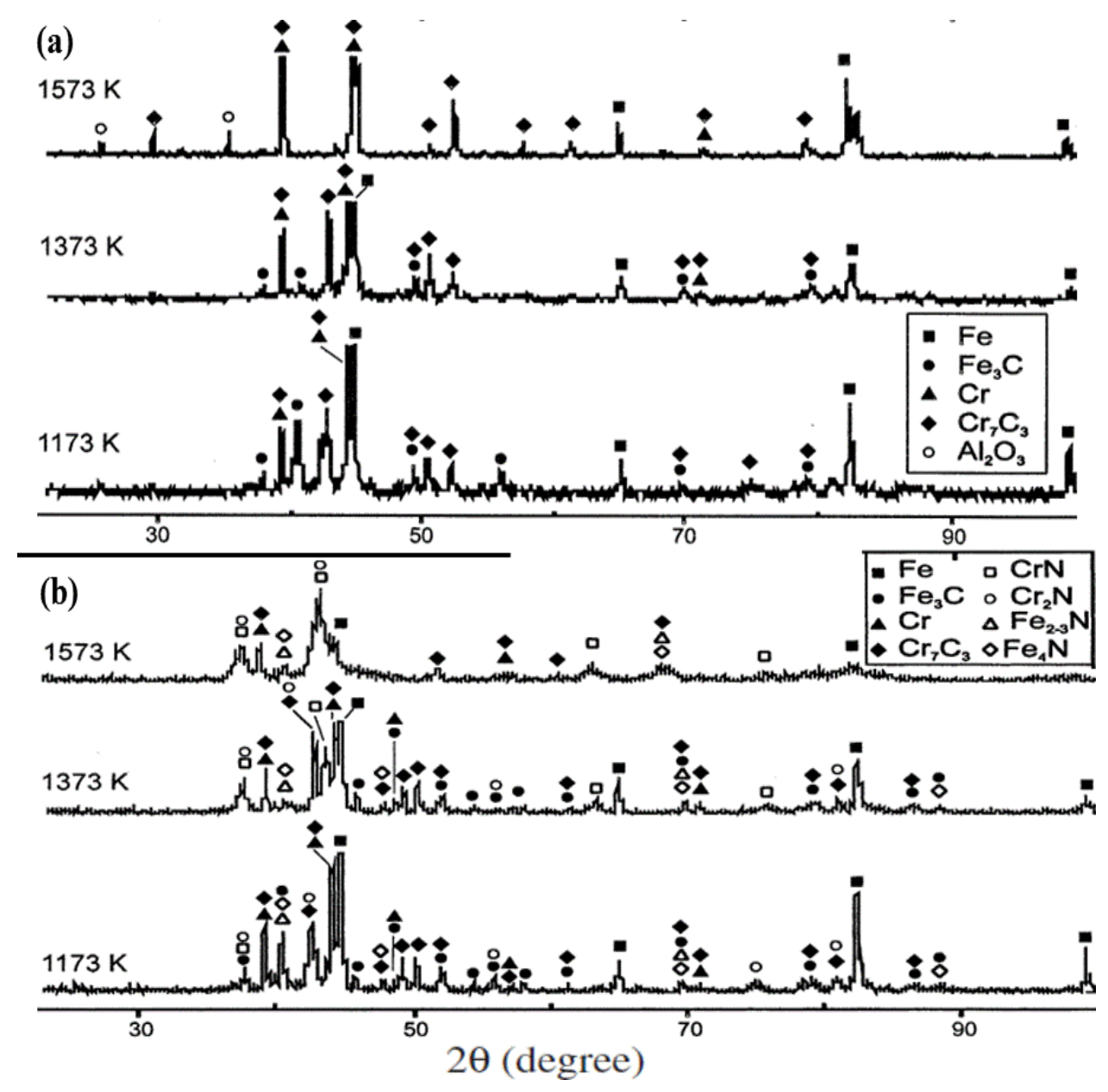

Fig. 9 XRD patterns (a) chromized AISI 1020 steel at different temperatures, (b) duplextreated AISI 1020 steel at different chromizing temperatures. The plasma nitriding was conducted for $1 \mathrm{~h}$ at $450{ }^{\circ} \mathrm{C}$ in $25 \% \mathrm{H}_{2}-75 \% \mathrm{~N}_{2}$ (Baggio-Scheid, De Vasconcelos et al. 2003).

The chromized surfaces of H13, AISI 1020 and A213 steels show similar XRD patterns and the types of carbides were identified to be $\mathrm{Cr}_{23} \mathrm{C}_{6}$ and $\mathrm{Cr}_{7} \mathrm{C}_{3}$ as shown in Fig. 10. After plasma nitriding $\left(1 \mathrm{~h}\right.$ at $\left.530^{\circ} \mathrm{C}\right)$ of the chromized AISI 1020 steel, the surface of the specimen contains not only the $\mathrm{CrN}$ phase, but $\gamma^{\prime}\left(\mathrm{Fe}_{4} \mathrm{~N}\right)$ nitride as well as $\varepsilon\left(\mathrm{Fe}_{2-3} \mathrm{~N}\right)$ nitride coexist (Fig. 11). The $\mathrm{CrN}$ layer mixed with iron nitrides is formed by a duplex treatment of plasma nitriding on chromized mild steel. Both AISI H13 and ASTM A213 steels show a similar tendency of the formation of chromium nitride and iron nitride layers and the layer's thickness was approximately 70-80 $\mu \mathrm{m}$. The results from the XRD analysis in Fig. 11 show similar diffraction regardless of the alloy types. Considering similar microstructure of the samples before plasma nitriding, except of the size of grain boundary carbides, all the results are understandable (Chang, Lee et al. 1999). 


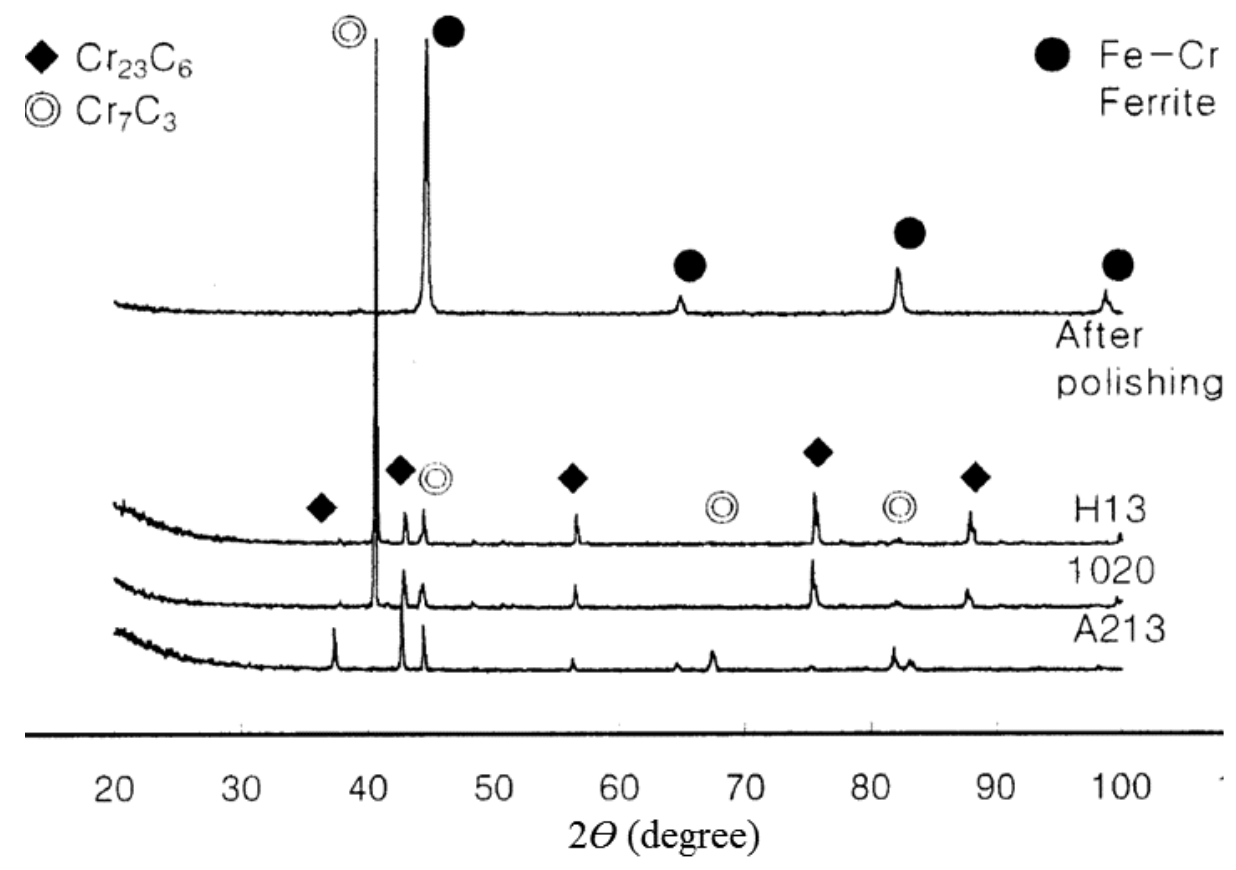

Fig. 10 XRD patterns of chromized specimens and after polishing the surface chromium carbide away(Chang, Lee et al. 1999).

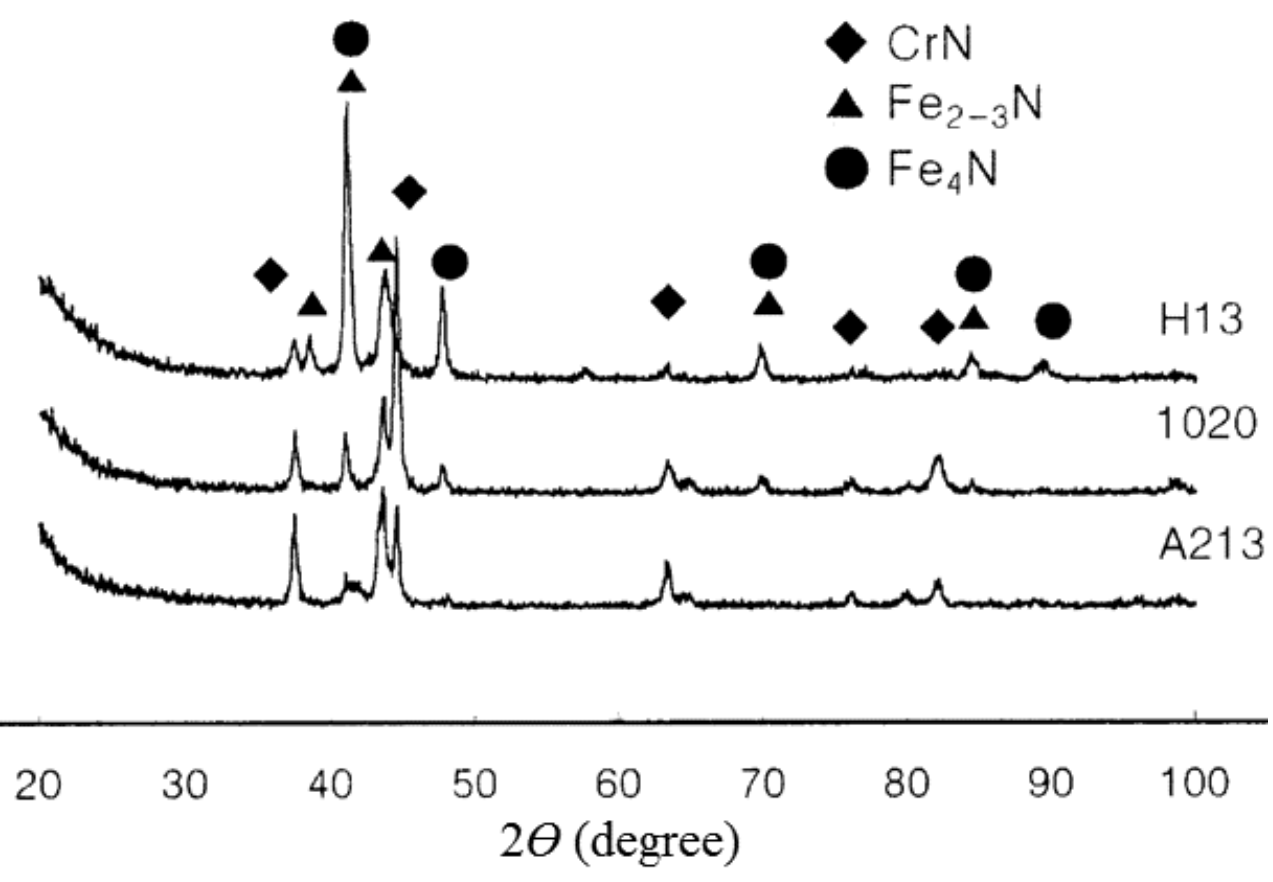

Fig. 11 XRD patterns of chromized and nitrided specimens (Chang, Lee et al. 1999)

Figs. 12 (a) and (b) show that the formed chromized surfaces of the AISI 52100 and 8620 steels contain major $\mathrm{Cr}_{3} \mathrm{C}_{2}$ and minor $\mathrm{Cr}_{7} \mathrm{C}_{3}$. However, after the duplex treatment $\mathrm{CrN}$ and $\mathrm{Cr}_{2} \mathrm{~N}$ as well as $\mathrm{Cr}_{3} \mathrm{C}_{2}$ and $\mathrm{Cr}_{7} \mathrm{C}_{3}$ were formed as shown in Figs. 12 (c) and (d). Fig. 13 demonstrates the X-ray diffraction patterns of the chromized and duplex treated AISI 52100 
and 8620 steels which show that major $\mathrm{Cr}_{3} \mathrm{C}_{2}$ and minor $\mathrm{Cr}_{7} \mathrm{C}_{3}$ are formed at the coated layers of the steels after TRD treatment. While XRD patterns of samples treated with the duplex process indicated that in addition to the formation of $\mathrm{Cr}_{3} \mathrm{C}_{2}$ and $\mathrm{Cr}_{7} \mathrm{C}_{3}$ carbides, dominant $\mathrm{CrN}$ and $\mathrm{Cr}_{2} \mathrm{~N}$ nitrides are formed, as shown in Fig. 13 (c) and (d).

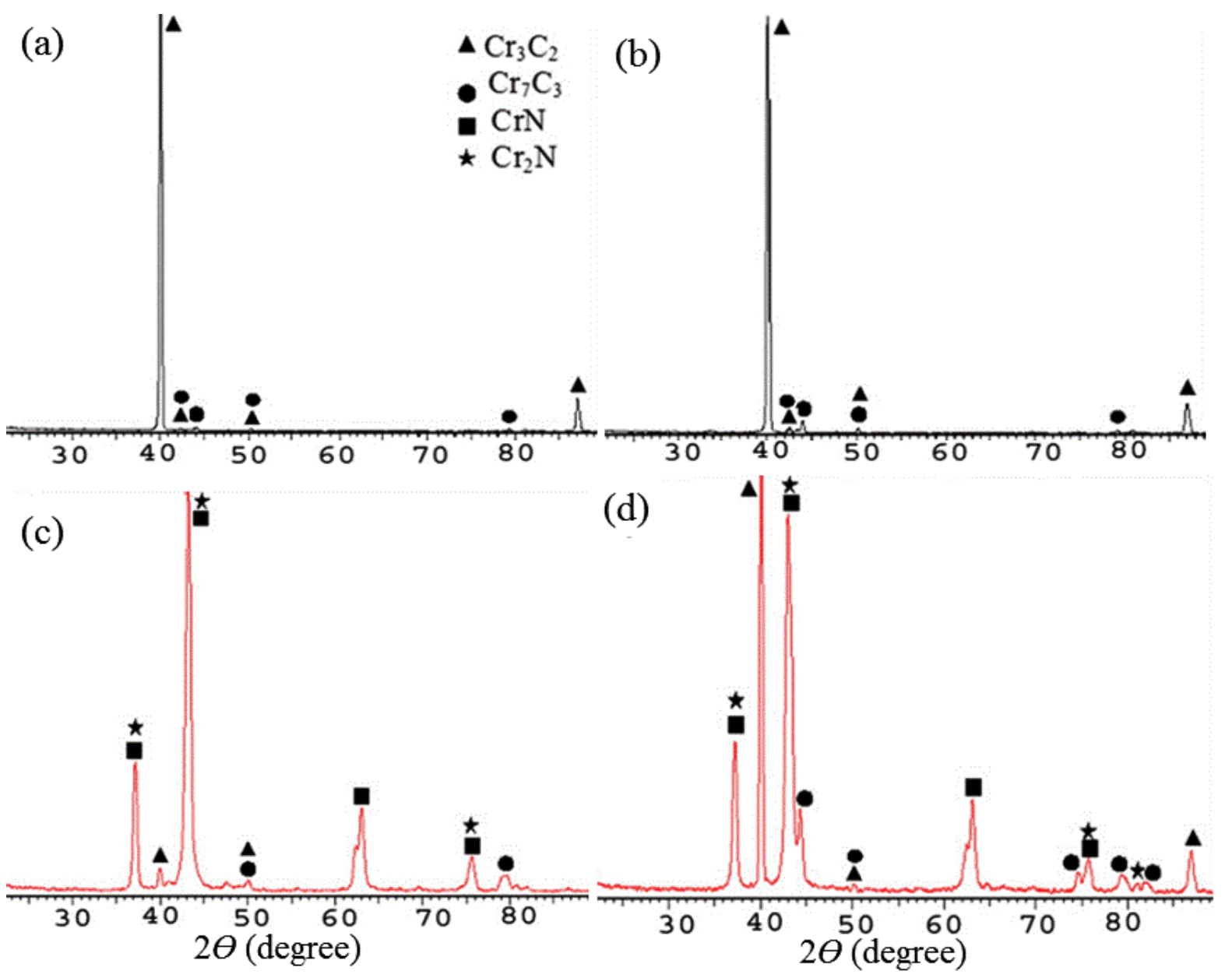

Fig. 12 XRD patterns of TRD chromized a) 52100, b) 8620 steels and duplex treated c) 52100, d) 8620 steels (Taktak, Ulker et al. 2008).

Wei and Chen (Wei and Chen 2005) noted that the thickness of chromized layer after plasma nitriding did not increase, but the composition of formed layer is changed. They believed that the nitrogen atoms substitute the carbon atoms in the chromized layer instead of overlaying them. In this study, it is observed that after plasma nitriding the thickness of compound layer is increased. It can be explained that the nitrogen atoms both substitute the carbon atoms in the chromized layer and overlay on the chromized layer, so the total compound layer increases. The decomposition of the carbides occurs only at the first moment of the sputtering treatment. A nitride layer is formed immediately after that and further layer growth is controlled by nitrogen diffusion (Taktak, Ulker et al. 2008). 
Fig. 13 demonstrates XRD results for duplex treated AISI 52100 and 8620 steels at various gas mixtures. The chromized layers contain $\mathrm{Cr}_{3} \mathrm{C}_{2}$ and $\mathrm{Cr}_{7} \mathrm{C}_{3}$ phases. X-ray diffraction patterns of the duplex treated samples indicated when steels duplex treated in gas mixture of $50 \% \mathrm{~N}_{2}+50 \% \mathrm{H}_{2}$ and $75 \% \mathrm{~N}_{2}+25 \% \mathrm{H}_{2}$, the intensity of chromium nitride peak increased compared with the samples duplex treated in a $25 \% \mathrm{~N}_{2}+75 \% \mathrm{H}_{2}$ plasma. On the other hand, no peaks that belong to chromium nitride phases were observed during duplex treatment at $100 \% \mathrm{~N}_{2}$ plasma (Taktak, Gunes et al. 2008).

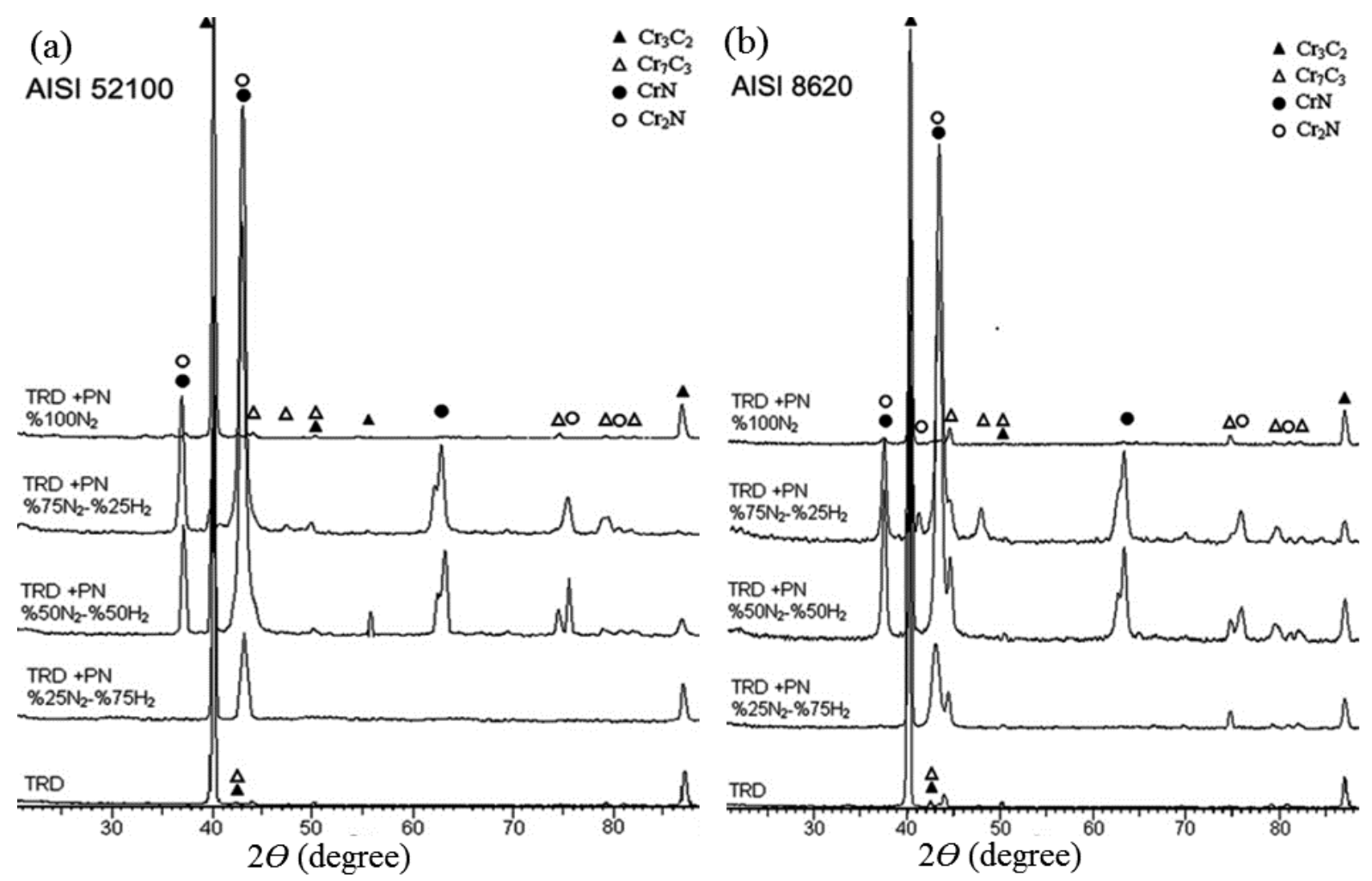

Fig. 13 XRD patterns of AISI 52100 and 8620 steels only TRD chromized and duplex treated at various gas mixtures(Taktak, Gunes et al. 2008).

Based on above discussion, it can be concluded that, after duplex treatment, the steel structure contain three distinctive layers: (i) $\mathrm{N}_{2}$-rich phases, (ii) $\mathrm{Cr}$-rich phases and (iii) a decarburized layer due to diffusion of carbon the layer (i) and (ii) due to its strong affinity towards $\mathrm{Cr}$. The whole process has shown schematically in Fig. 14. After plasma nitriding of chromized layer $\mathrm{CrN}$ or $\mathrm{Cr}_{2} \mathrm{~N}$ nitrides are formed in duplex layer. One factor that affects chromium nitride composition is plasma nitriding temperature. 


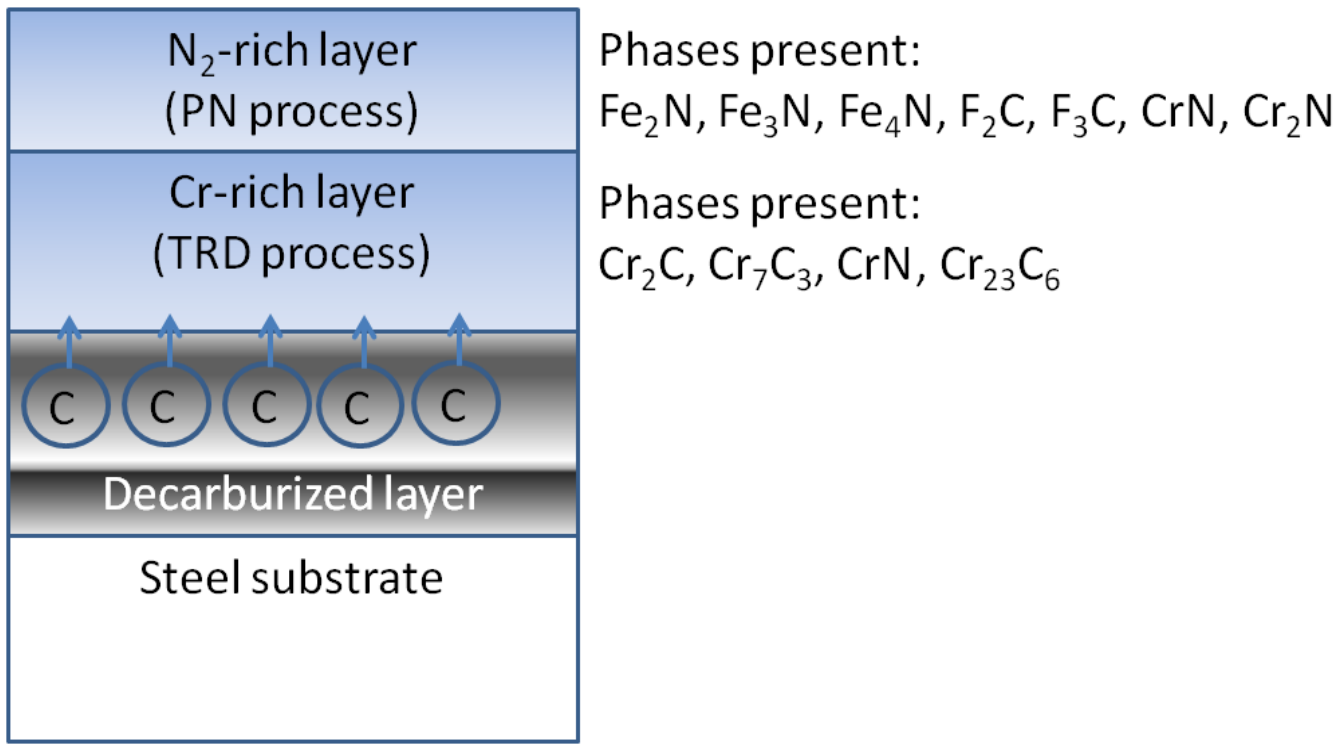

Fig. 14 Schematic representation of different layers (with corresponding phases) that form during duplex treatment of steels.

\section{Surface hardness and roughness}

The hardness of the treated surface increases with every stage of duplex treatment. The surface hardness of the chromized layer of AISI 1045 steel, duplex treated layers nitrided at $500{ }^{\circ} \mathrm{C}$, and $550{ }^{\circ} \mathrm{C}$ was $1270 \pm 10 \mathrm{HV}_{0.1}, 1540 \pm 20 \mathrm{HV}_{0.1}$ and $1420 \pm 10 \mathrm{HV}_{0.1}$, respectively. Increase of surface hardness after nitriding was probably because formation of $\mathrm{Cr}_{\mathrm{x}} \mathrm{N}$ and $\mathrm{Fe}_{\mathrm{x}} \mathrm{N}$ phases by duplex treatment. When nitriding temperature was increased to $550{ }^{\circ} \mathrm{C}$, the hardness decreased. It can be related to reduction of the thickness of the treated layer at higher temperature (Hakami, Sohi et al. 2011). During microhardness measurements the load must be high enough to produce an indentation which is easy to measure by an optical microscope. Usually this requirement extends the plastic deformation zone into the substrate, thus the result is a combination of coating and substrate microhardness (Pramanik, Zhang et al. 2007, Pramanik, Zhang et al. 2008). This can be avoided by measuring hardness in crosssection as discussed in next paragraph. In addition, formation of $\mathrm{CrN}$ and $\mathrm{Fe}_{4} \mathrm{~N}$ at $550{ }^{\circ} \mathrm{C}$ instead of $\mathrm{Cr}_{2} \mathrm{~N}$ and $\mathrm{Fe}_{3} \mathrm{~N}$ at $500{ }^{\circ} \mathrm{C}$ also affects the surface hardness. Fig. 15 indicates the hardness profiles of chromized and post nitrided samples at different temperatures that show similar behaviour. The hardness profiles of the duplex treated materials show two step decrease since, nitrogen has only diffused partly in the chromized layer during post plasma nitriding (Hakami, Sohi et al. 2011). 


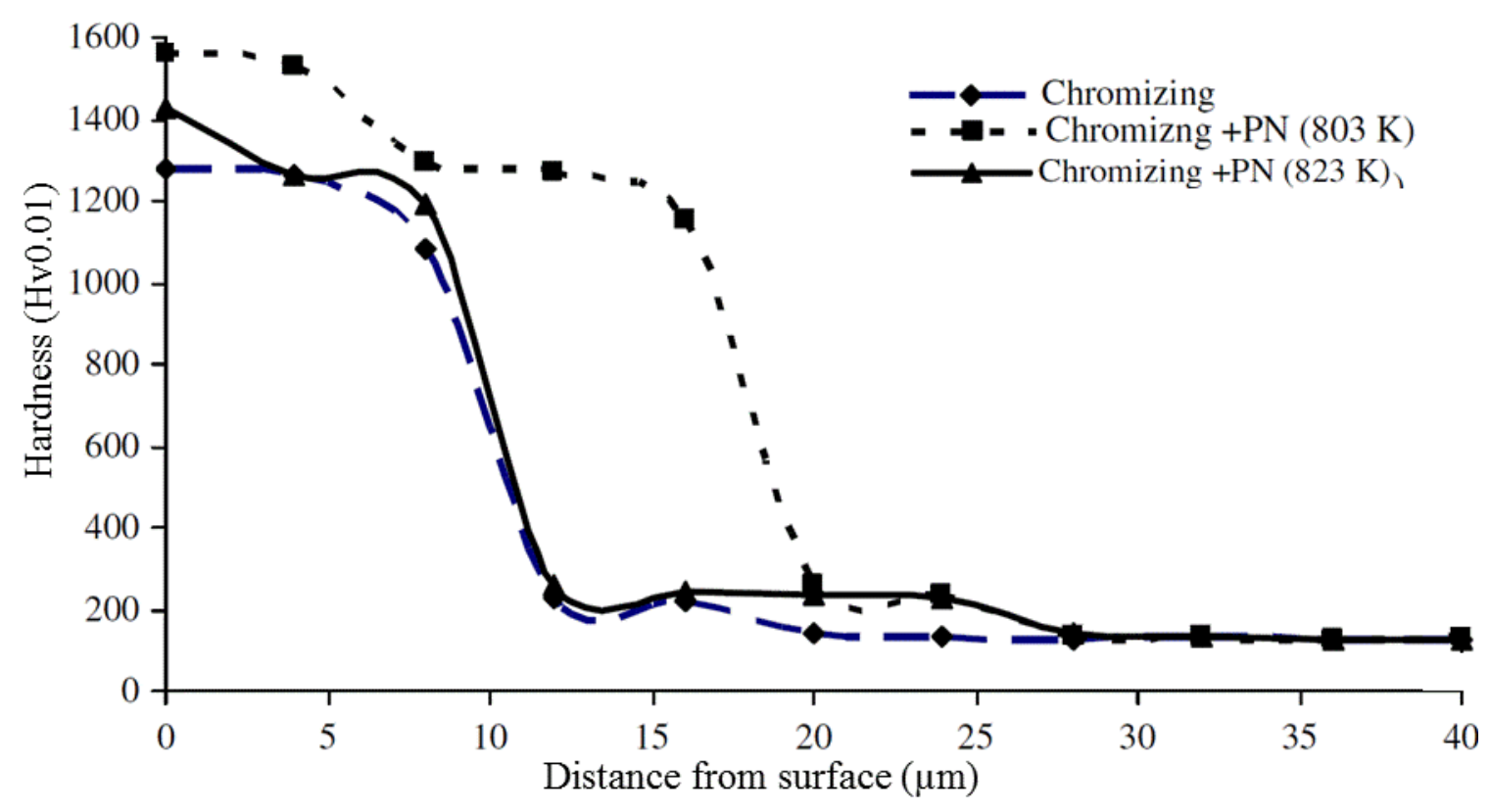

Fig. 15 The hardness profiles of chromized and post nitrided samples at different temperatures(Hakami, Sohi et al. 2011).

Results obtained from the surface microhardness measurements are indicated in Table 6. For the AISI 1020 samples, which were only nitrided, white layer thicknesses was between 2 and $4 \mathrm{~mm}$ and hardness was $490 \mathrm{HV}_{0.1}$. This layer consists of $\mathrm{FeN}, \mathrm{Fe}_{4.4} \mathrm{~N}$ and $\mathrm{Fe}_{2-3} \mathrm{~N}$ nitrides. A diffusion layer with a thickness of approximately $130 \mu \mathrm{m}$ seems to be formed. However, a decrease in hardness near the surface was possibly caused by decarburization during the nitriding process as shown in the hardness profile in Fig. 16. With increase of the thickness of chromized layer, the hardness of the layer increases. The microhardness profile of the chromized sample at $1300{ }^{\circ} \mathrm{C}$ shows that the hardness decreases linearly from $445 \mathrm{HV}_{0.1}$ to $380 \mathrm{HV}_{0.1}$ at the end of the diffusion layer which indicates a slight reduction in the chromium concentration. The hardness of the samples which are treated by the duplex process also increases with increasing chromizing temperature; however, their hardness was approximately $50 \mathrm{HV} 0.1$ below that obtained for the chromized samples. This reduction in hardness was observed for temperatures below $1100{ }^{\circ} \mathrm{C}$, since a thin chromized layer is formed during the nitriding process at $450{ }^{\circ} \mathrm{C}$. 
Table 6. Surface microhardness of nitrided, chromized and duplex-treated samples for different chromizing temperatures (Baggio-Scheid, De Vasconcelos et al. 2003)

\begin{tabular}{|lccccc|}
\hline Process & \multicolumn{2}{l|}{ Surface microhardness $\left(\mathrm{HV}_{0.1}\right)$} \\
\hline \multicolumn{7}{|c|}{ Chromizing temperature $\left({ }^{\circ} \mathrm{C}\right)$} \\
\hline Nitriding & 402 & 900 & 1000 & 1100 & 1200 \\
Chromizing & & & & & \\
Duplex & 231 & 291 & 328 & 347 & 445 \\
\hline
\end{tabular}

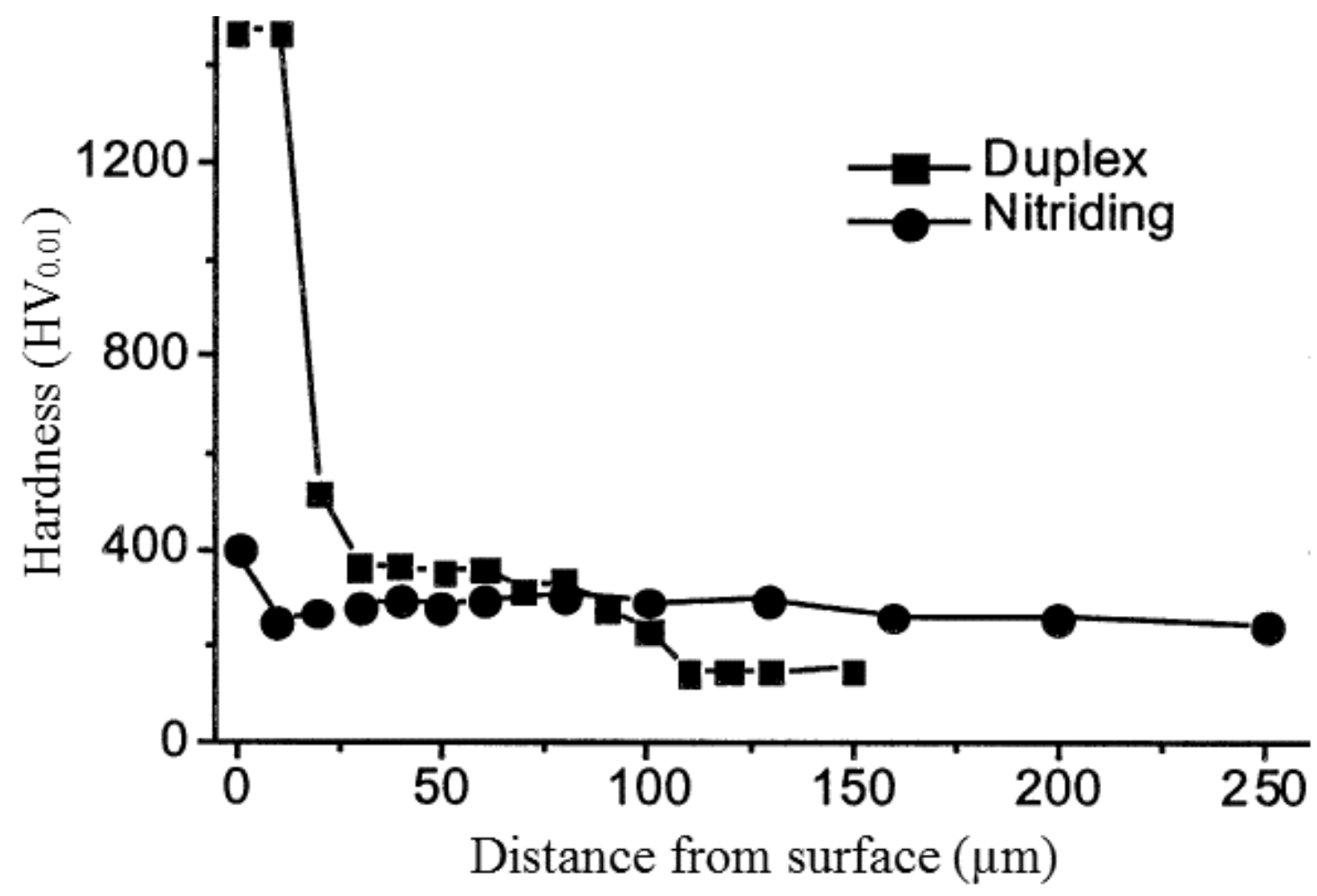

Fig. 16 Cross-sectional micro-Vickers hardness profiles of plasma-nitrided $\left(1 \mathrm{~h}\right.$ at $450{ }^{\circ} \mathrm{C}$ in $\mathrm{H}_{2}-75 \% \mathrm{~N}_{2}$ ) and duplex-treated (chromizing for $5 \mathrm{~h}$ at $1300{ }^{\circ} \mathrm{C}$; plasma nitriding for $1 \mathrm{~h}$ at $450{ }^{\circ} \mathrm{C}$ in $\mathrm{H}_{2}-75 \% \mathrm{~N}_{2}$ ) samples (Baggio-Scheid, De Vasconcelos et al. 2003).

Fig. 17 shows that the surface microhardness of the duplex-treated AISI 1020, i.e. chromized and plasma nitrided AISI 1020, is in the range of $1400-1500 \mathrm{HV}_{0.1}$ and reduces to approximately $1300 \mathrm{HV}_{0.1}$ at the interface between the duplex-treated layer and the chromized layer since the amount of nitrogen decreases towards the matrix. It is mentioned that the microhardness in the duplex-treated layer is slightly lower than the hardness of $\mathrm{Cr}_{x} \mathrm{~N}$ 
coating layer obtained by PVD process, which is approximately $1600-2000 \mathrm{H}_{\mathrm{v}}$ (Hurkmans, Lewis et al. 1996). This could be due to the fact that in addition to CrN phase, there are other phases such as $\gamma^{\prime}\left(\mathrm{Fe}_{4} \mathrm{~N}\right)$ and $\varepsilon\left(\mathrm{Fe}_{2-3} \mathrm{~N}\right)$ in the chromized and plasma nitrided layer, compared with the single $\mathrm{CrN}$ or $\mathrm{Cr}_{x} \mathrm{~N}$ phase obtained by PVD process, since iron nitrides hardness is slightly lower than chromium nitrides. In the duplex-treated layer in AISI 1020 a relatively high microhardness of more than $1300 \mathrm{HV}_{0.1}$ could be obtained. The microhardness distribution of AISI H13 and ASTM A213 steels are similar to that of AISI 1020 (Chang, Lee et al. 1999).

Table 7 indicates results obtained from surface microhardness, critical loads and roughness measurements for the chromized and duplex treated steels. $\mathrm{L}_{\mathrm{C} 1}$ and $\mathrm{L}_{\mathrm{C} 2}$ are the lower and upper critical load, respectively. The microhardness of the TRD chromized layers were around $1823 \pm 24$ and $1769 \pm 35 \mathrm{HK}_{0.025}$, which have increased after duplex treatment to $2135 \pm 56$ and $1976 \pm 45 \mathrm{HK}_{0.025}$ for 52100 and 8620 steels, respectively. After chromizing, the main chromium carbide composition is $\mathrm{Cr}_{3} \mathrm{C}_{2}$ which has higher hardness and stability compare to other chromium carbides $\left(\mathrm{Cr}_{7} \mathrm{C}_{3}\right.$ and $\left.\mathrm{Cr}_{23} \mathrm{C}_{6}\right)$ (Wang, Weng et al. 1999). The amount of microhardness on chromized layer of AISI 52100 is higher compared with chromized AISI 8620 steel. This could be due to high amount of carbon in the 52100 steel (Lee and Duh 2004). Because formation of $\mathrm{Cr}_{\mathrm{x}} \mathrm{N}$ phase, the microhardness values in the duplex treated layers were higher than microhardness amount of chromized layers. Unlike the previous study (Chang, Lee et al. 1999), the reported microhardness values of duplex treated steels were almost equal to CrN layers produced by PVD process, which is approximately 1600-2000 HV (Hurkmans, Lewis et al. 1996). As seen in Table 7, surface process steps have influenced surface roughness of steels. After chromizing and plasma nitriding process the surface roughness enhanced to about $0.4 \mu \mathrm{m}$ and $0.6 \mu \mathrm{m}$, respectively. This might be due to the intrinsic properties of formed phases. It is also well known that surface treatments amplify the surface roughness (Taktak, Ulker et al. 2008). 


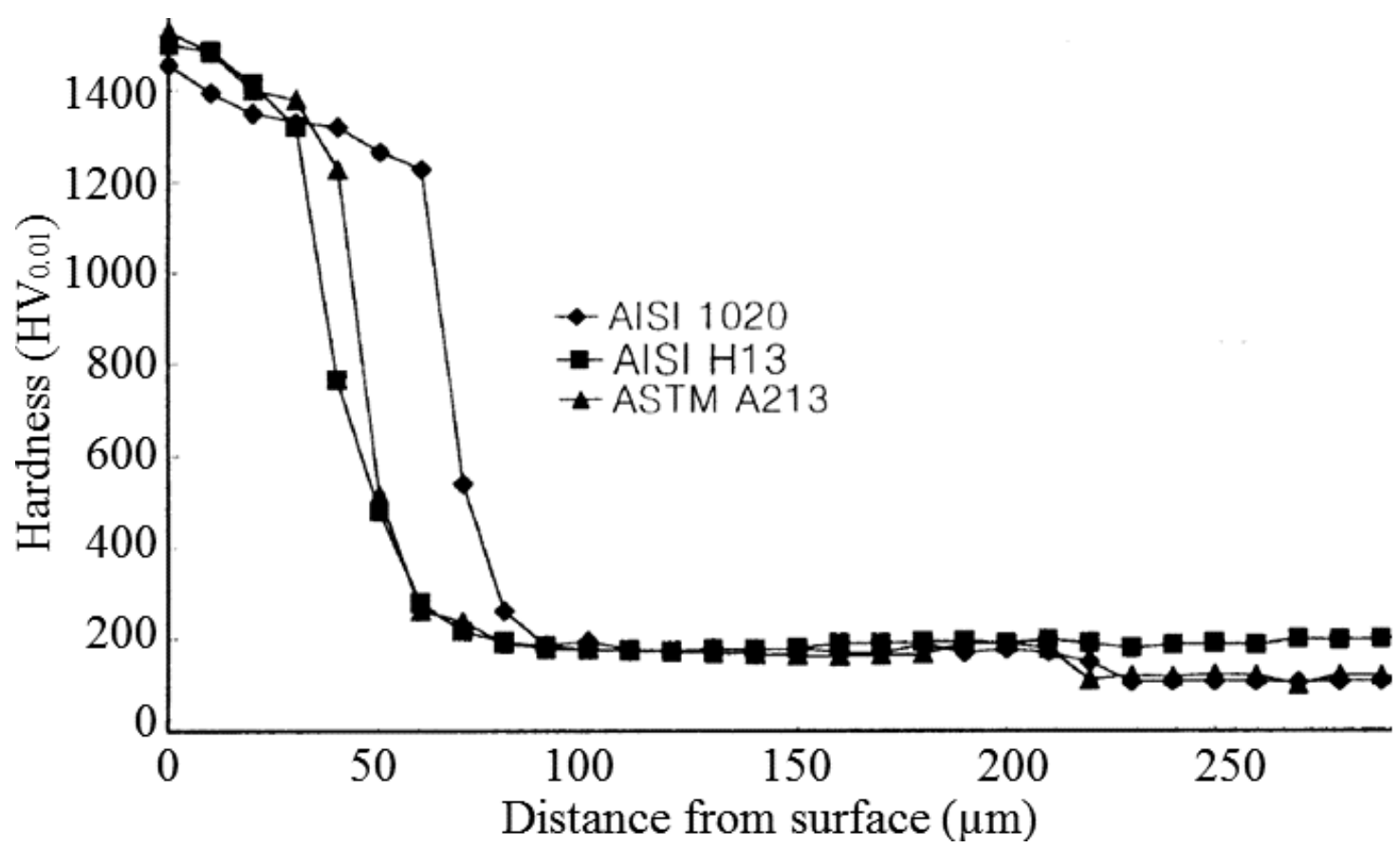

Fig. 17 Cross-sectional micro-Vickers' hardness profiles of chromized and nitrided specimens(Chang, Lee et al. 1999).

Table 7. Hardness, critical loads and surface roughness values of TRD chromized and duplex treated (TRD + plasma nitriding) AISI 52100 and 8620 steels (Taktak, Ulker et al. 2008)

\begin{tabular}{|l|c|cc|c|}
\hline Samples & $\begin{array}{c}\text { Microhardness, } \\
\mathrm{HK}_{0.025}\end{array}$ & Critical Load, N & $\begin{array}{c}\text { Surface } \\
\text { Roughness, } \mathrm{R}_{\mathrm{a}} \\
(\mu \mathrm{m})\end{array}$ \\
\hline & & & & \\
\hline Chromized 52100 & $1823 \pm 24$ & 11.7 & 76.3 & $0.42 \pm 0.04$ \\
Duplex treated 52100 & $2135 \pm 56$ & 29.4 & 81 & $0.634 \pm 0.1$ \\
Chromized 8620 & $1769 \pm 35$ & 21.2 & 71 & $0.415 \pm 0.06$ \\
Duplex treated 8620 & $1976 \pm 45$ & 22 & 73.8 & $0.612 \pm 0.08$ \\
\hline
\end{tabular}

Table 8 shows surface microhardness and roughness for AISI 52100 and 8620 steels after chromizing and duplex treatment at various plasma gas mixtures. The microhardness of the duplex treated steels increases with an increase in nitrogen content in $\mathrm{N}_{2}+\mathrm{H}_{2}$ gas mixtures. However, hardness of duplex treated steels, nitrided at $100 \% \mathrm{~N}_{2}$ plasma, was lower than the hardness of duplex treated samples at gas mixtures which contains $\mathrm{H}_{2}$. This can be attributed to the absence of chromium nitride phases in the surface layer (formed at $100 \% \mathrm{~N}_{2}$ plasma) 
which was confirmed by the X-ray diffraction. It is shown (Table 8) that the surface roughness is affected by surface treatment steps and amount of gas mixtures. A polished surface roughness of $0.03 \mu \mathrm{m} \mathbf{R}_{\mathrm{a}}$ increased to about $0.4 \mu \mathrm{m}$ after the chromizing process, and with increasing nitrogen content in the plasma nitriding process, the surface roughness increases (Taktak, Gunes et al. 2008).

Table 8 Microhardness and surface roughness of TRD chromized and duplex treated $($ TRD + PN) AISI 52100 and 8620 steels (Taktak, Gunes et al. 2008)

\begin{tabular}{|c|c|c|c|c|c|}
\hline \multirow{2}{*}{$\begin{array}{c}\text { Treatment } \\
\text { type }\end{array}$} & \multirow{2}{*}{$\begin{array}{l}\text { Plasma nitriding } \\
\text { (PN) gas } \\
\text { compositions }\end{array}$} & \multicolumn{2}{|c|}{ Microhardness, $\mathrm{HK}_{0.025}$} & \multicolumn{2}{|c|}{ Surface roughness, $R_{a}(\mu m)$} \\
\hline & & AISI 52100 & AISI 8620 & AISI 52100 & AISI 8620 \\
\hline TRD & - & 1823 & 1769 & $0.42 \pm 0.04$ & $0.415 \pm 0.06$ \\
\hline $\mathrm{TRD}+\mathrm{PN}$ & $25 \% \mathrm{~N}_{2}-75 \% \mathrm{H}_{2}$ & 1867 & 1835 & $0.610 \pm 0.09$ & $0.604 \pm 0.11$ \\
\hline $\mathrm{TRD}+\mathrm{PN}$ & $50 \% \mathrm{~N}_{2}-50 \% \mathrm{H}_{2}$ & 2135 & 1976 & $0.634 \pm 0.10$ & $0.612 \pm 0.08$ \\
\hline $\mathrm{TRD}+\mathrm{PN}$ & $75 \% \mathrm{~N}_{2}-25 \% \mathrm{H}_{2}$ & 2438 & 2287 & $0.703 \pm 0.08$ & $0.688 \pm 0.07$ \\
\hline $\mathrm{TRD}+\mathrm{PN}$ & $100 \% \mathrm{~N}_{2}$ & 1854 & 1795 & $0.708 \pm 0.23$ & $0.727 \pm 0.20$ \\
\hline
\end{tabular}

The obtained microhardness result of duplex treated layer showed that duplex layer hardness is higher than the chromized or nitrided layer, due to formation of $\mathrm{Cr}_{\mathrm{X}} \mathrm{N}$ and $\mathrm{Fe}_{\mathrm{x}} \mathrm{N}$ phases by duplex treatment. .

\section{Wear and friction}

Improvement of wear resistance is one of the main objectives of surface treatment. Duplex plasma nitriding of chromized layer has been tested for wear resistance and improved wear resistance is noted. Table 9 presents the methods and conditions of wear tests performed by several researchers for different steels after duplex treatment.

Table 9 wear methods and conditions

\begin{tabular}{ccccc}
\hline Reference & Method & Sliding distance $(\mathrm{m})$ & Load $(\mathrm{N})$ & Temp $\left({ }^{\circ} \mathrm{C}\right)$ \\
\hline (Hakami, Sohi et al. 2011) & Pin on disk & 500 & 7 & 25 \\
(Chang, Lee et al. 1999) & Ball on disk & 2000 & 4 & 600 \\
(Taktak, Ulker et al. 2008) & Ball on disk & 1080 & $5 \& 20$ & 500 \\
(Taktak, Gunes et al. 2008) & Ball on disk & 1080 & $5 \& 20$ & 500 \\
\hline
\end{tabular}

Wear rates variation for the chromized AISI 1045 sample and post plasma nitrided samples with surface hardness are illustrated in Fig. 18. It can be seen that samples which are 
chromized and plasma nitrided at $530{ }^{\circ} \mathrm{C}$ with the highest surface hardness has the lowest wear rate. Wear rate results are confirmed by the SEM micrographs of the wear tracks of the chromized sample as well as post nitrided specimens at $530{ }^{\circ} \mathrm{C}$ and $550{ }^{\circ} \mathrm{C}$, as shown in Fig. $19(\mathrm{a}-\mathrm{c})$. The width of the wear tracks of the chromized sample and, post nitrided samples at $530{ }^{\circ} \mathrm{C}$ and $550^{\circ} \mathrm{C}$ is 625,506 and $576 \mu \mathrm{m}$, respectively. The lowest width belongs to the sample post nitrided at $530{ }^{\circ} \mathrm{C}$ which showed the lowest wear rate. Average friction coefficients at steady state regime for chromized and post plasma nitrided samples at $530{ }^{\circ} \mathrm{C}$ and $550{ }^{\circ} \mathrm{C}$ were around $0.6,0.3$, and 0.4 , respectively. It is seen that post plasma nitriding decreases plasma nitride at $530{ }^{\circ} \mathrm{C}$ exhibited the lowest friction coefficient $(0.3)$ probably due to its higher hardness (Hakami, Sohi et al. 2011).

Chang et al., (Chang, Lee et al. 1999) investigated wear of surface treated layers at $600{ }^{\circ} \mathrm{C}$. The results showed that the chromized AISI 1020 and H13 steel have a poor wear resistance than the duplex-treated specimens. The lowest friction coefficient belongs to duplex-treated specimen. The high surface hardness and deep case in the duplex-treated specimen are the main reasons of excellent wear resistance at $600{ }^{\circ}$ C. Figs. 20 ((a) and (b)) show the wear tracks after wear test at $600{ }^{\circ} \mathrm{C}$ on chromized and duplex-treated specimens AISI H13. Regardless of the alloy compositions the wear tracks of the duplex-treated specimen showed an abrasive type wear while the chromized specimens showed an adhesive type wear (Chang, Lee et al. 1999).

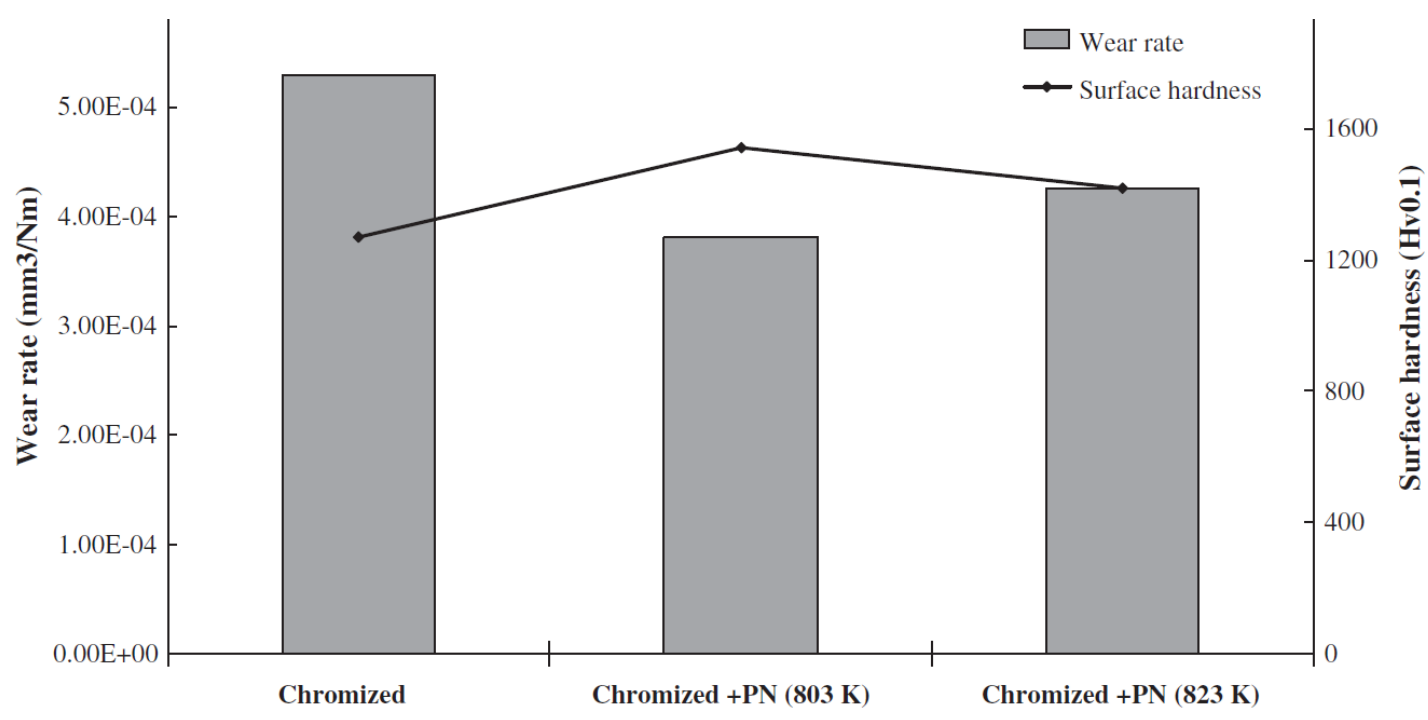

Fig. 18 Variation of the wear rates and surface hardness of the chromized sample and post plasma nitrided samples (Hakami, Sohi et al. 2011) 

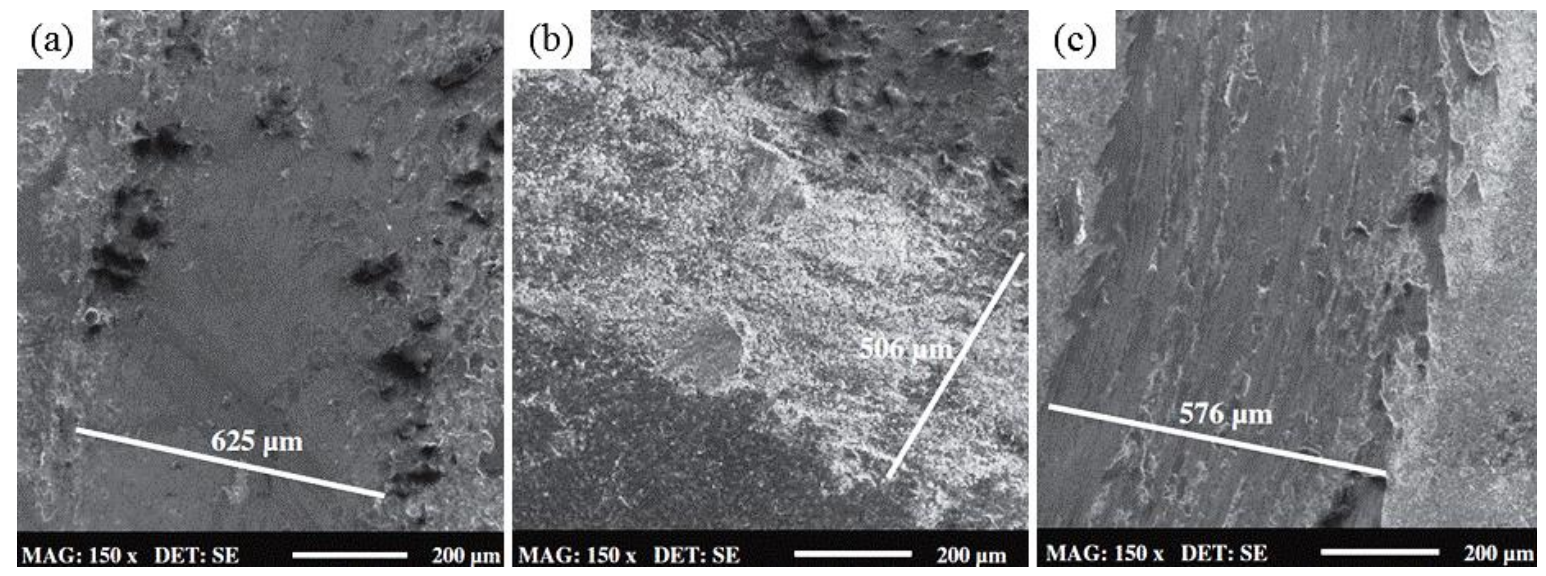

Fig. 19 SEM micrograph of the wear tracks of the AISI 1045 steel after chromizing (a), and chromizing and post nitriding at $530{ }^{\circ} \mathrm{C}$ (b), and $550{ }^{\circ} \mathrm{C}$ (c)(Hakami, Sohi et al. 2011).

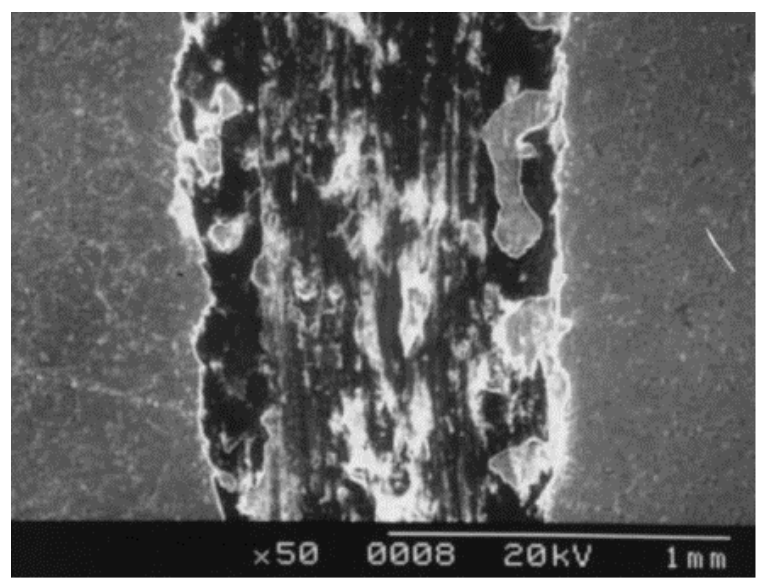

(a) Chromized AISI H13

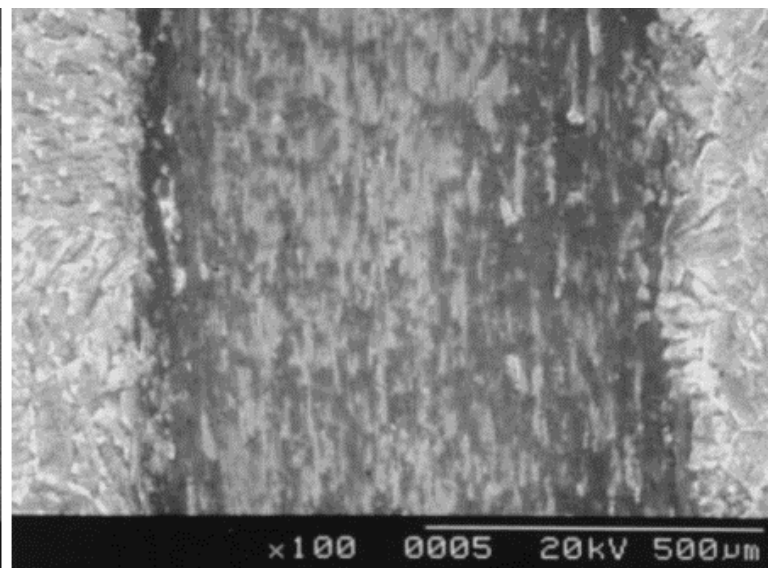

(b) Chromized and nitrided AISI H13

Fig. 20Wear tracks of AISI H13 (a) chromized and (b)chromized and nitrided (Chang, Lee et al. 1999).

Steady state friction coefficients of chromized and duplex treated AISI 52100 and 8620 steels for 5 and $20 \mathrm{~N}$ loads at room temperature and $500{ }^{\circ} \mathrm{C}$ are illustrated in Fig. 21. It shows that plasma nitriding process reduces the friction coefficient of chromized steels at both temperatures. This can be due to lower friction coefficient of chromium nitride. It also shows that samples at room temperature (R.T.) have lower friction coefficient than samples at 500 ${ }^{\circ} \mathrm{C}$. The steady state friction coefficient of chromized (TRD) AISI 8620 and 52100 bearing steels for loads of 5 and $20 \mathrm{~N}$ was in order of $0.63-0.75$ at R.T. that dropped to $0.43-0.53$ at temperature of $500{ }^{\circ} \mathrm{C}$. The steady state friction coefficient of duplex treated (TRD+PN) bearing steels for loads of 5 and $20 \mathrm{~N}$ was in order of $0.55-0.41$ at R.T. which dropped to in order of $0.47-0.38$ at temperature of $500{ }^{\circ} \mathrm{C}$. The decrease of the coefficient of friction of the chromized and duplex treated steels at high temperature may be due to decrease of hardness 
and shear strength of coating and formation of oxides in the wear track. Oxides especially chromium oxide, reduces the friction. It is reported that, $\mathrm{CrO}_{2}$ film formed at $450{ }^{\circ} \mathrm{C}$ on $\mathrm{Cr}_{2} \mathrm{O}_{3}$ layer is effective in reduction of the friction (Taktak, Ulker et al. 2008).
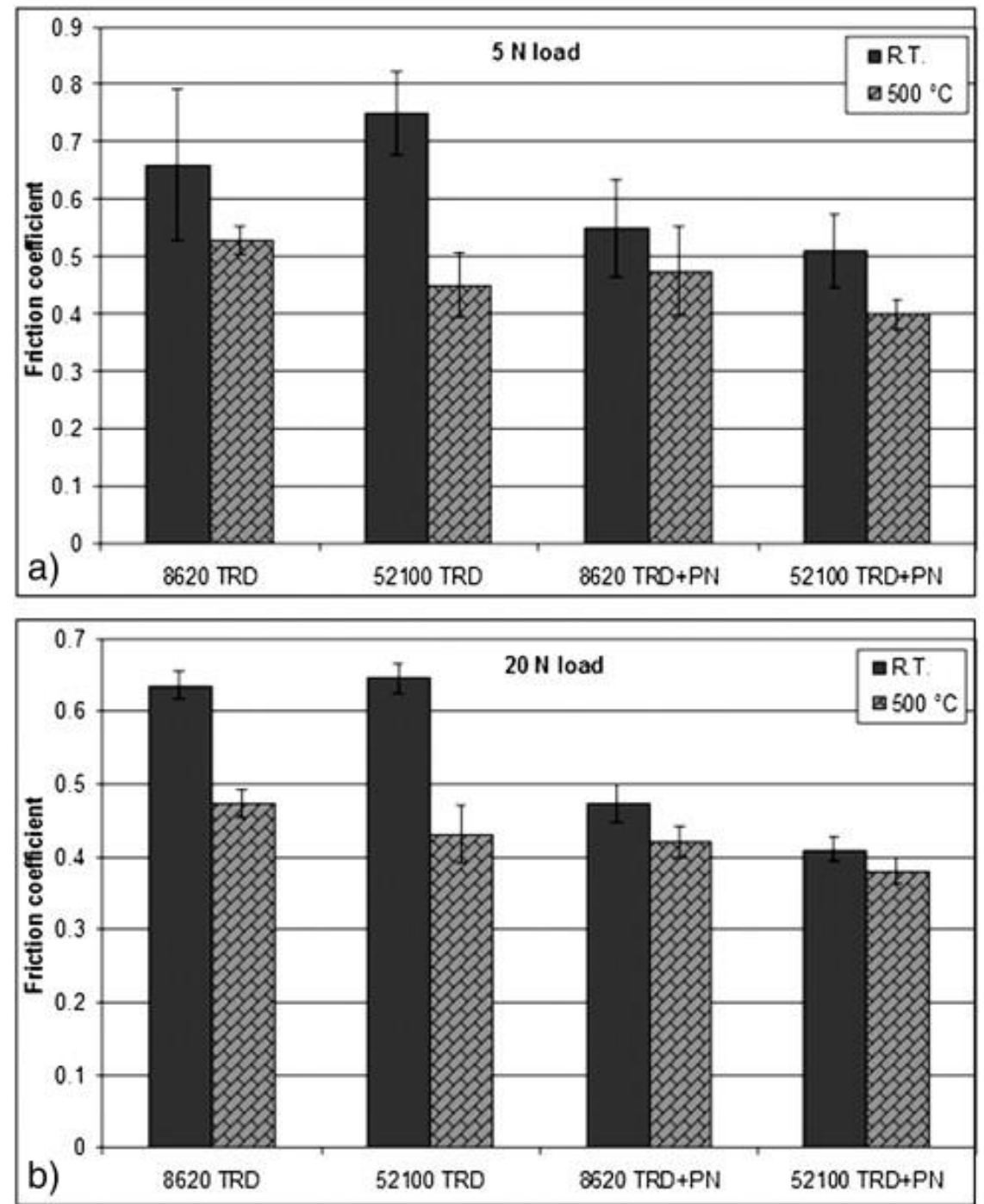

Fig. 21 Steady state friction coefficient values at room temperature and $500{ }^{\circ} \mathrm{C}$ for TRD chromized and duplex treated (TRD + PN) AISI 52100 and 8620 steels under loads of a) $5 \mathrm{~N}$ and b) $20 \mathrm{~N}$.

Taktak et al., (Taktak, Ulker et al. 2008) noted that unlike the coefficient of friction graphs, the wear rates of the chromized and duplex treated steel increased at $500{ }^{\circ} \mathrm{C}$. The wear rates of chromized AISI 52100 steel for $5 \mathrm{~N}$ load were $11.4 \times 10^{-6}$ and $14.45 \times 10^{-6} \mathrm{~mm}^{3} / \mathrm{Nm}$ at room temperature and $500{ }^{\circ} \mathrm{C}$, while the wear rates of duplex treated steels were $6.2 \times 10^{-6}$ and $8.4 \times 10^{-6} \mathrm{~mm}^{3} / \mathrm{Nm}$, respectively. The best wear resistance belongs to duplex treated AISI 52100 steel, while chromized AISI 8620 steel showed the worse wear resistance. This might 
be attributed to better wear resistance of chromium nitride in comparison with chromium carbide coating (Wei and Chen 2005). The morphology of wear track of steel was rough with the evidence of plastic deformation, ploughings and small debris of the chromium carbide coating. The chromium carbide coating was peeled from the substrate during sliding on the chromized steel at room temperature. The oxidation of the chromized steels increased and sliding occurred on the oxide layers with rise of temperature up to $500{ }^{\circ} \mathrm{C}$. In addition, the tribooxidation also plays an important role in friction as the wear track is more oxidized than the surface outside of the contact area. Deep scratches parallel to relative movement appeared in the wear track which can be because of spontaneous oxidation of the coating that enhances the production of $\mathrm{Cr}_{2} \mathrm{O}_{3}$ which causes abrasive wear. The EDX spectrums displayed that the worn surfaces contained oxygen and oxygen concentration increased with temperature. The worn surface was covered with a discontinuous oxidized compact layer as well as grooves, many cracks and plate oxide debris appeared on the compact layer (Taktak, Ulker et al. 2008).

The wear track of duplex treated steel was relatively smooth and flat without evidence of strong ploughing or groove, thus polishing wear occurred. Shallow wear track and worn $\mathrm{Al}_{2} \mathrm{O}_{3}$ ball for duplex treated steel were noted when compared with wear tracks of chromized steels. This could be due to high surface hardness and deep case of duplex treated steels. Diameter of ball was low and disc material transfer to the ball was apparent during wear test at $500{ }^{\circ} \mathrm{C}$ on the duplex treated steel compared to that in room temperature. The wear track illustrated that unlike the chromized steel, the surface had been almost completely covered with an oxide film. Small holes, cracks and delaminated wear debris are noted on the compact layer which suggest that the fracture wear of the oxide tribolayer occurred more frequently by delamination wear and the delamination results in crack propagation. The compact layer forms due to material transfer as well as plastic deformation of the surface layer. Several studies about high temperature wear of ceramics and ceramic based coatings reported formation of similar compact layer as a consequence of debris sintering effects(Yang, Senda et al. 2004). Wear debris particles are produced during the sliding, which retained within the contacting surfaces and are sintered together to form solid compact layers. Such sintering of fine particles can occur at high temperatures. Because of chemical sintering effect between particles, oxidational environment also facilitates the stabilization of these layers (Taktak, Ulker et al. 2008). 
Fig. 22 shows steady state friction coefficient values of the chromized (TRD) and duplex treated $(\mathrm{TRD}+\mathrm{PN})$ steels at various gas mixtures, for loads of 5 and $20 \mathrm{~N}$. The error bars indicate the variation of the friction coefficient after steady state was reached. The obtained results showed that the duplex treated samples in a gas mixture of $50 \% \mathrm{~N}_{2}+50 \% \mathrm{H}_{2}$, have the lowest steady state friction coefficient, followed by the samples duplex treated in the gas mixture of $25 \% \mathrm{~N}_{2}+75 \% \mathrm{H}_{2}$ (Taktak, Gunes et al. 2008). This might be due to the lower friction coefficient of chromium nitride (Bull and Rickerby 1990).

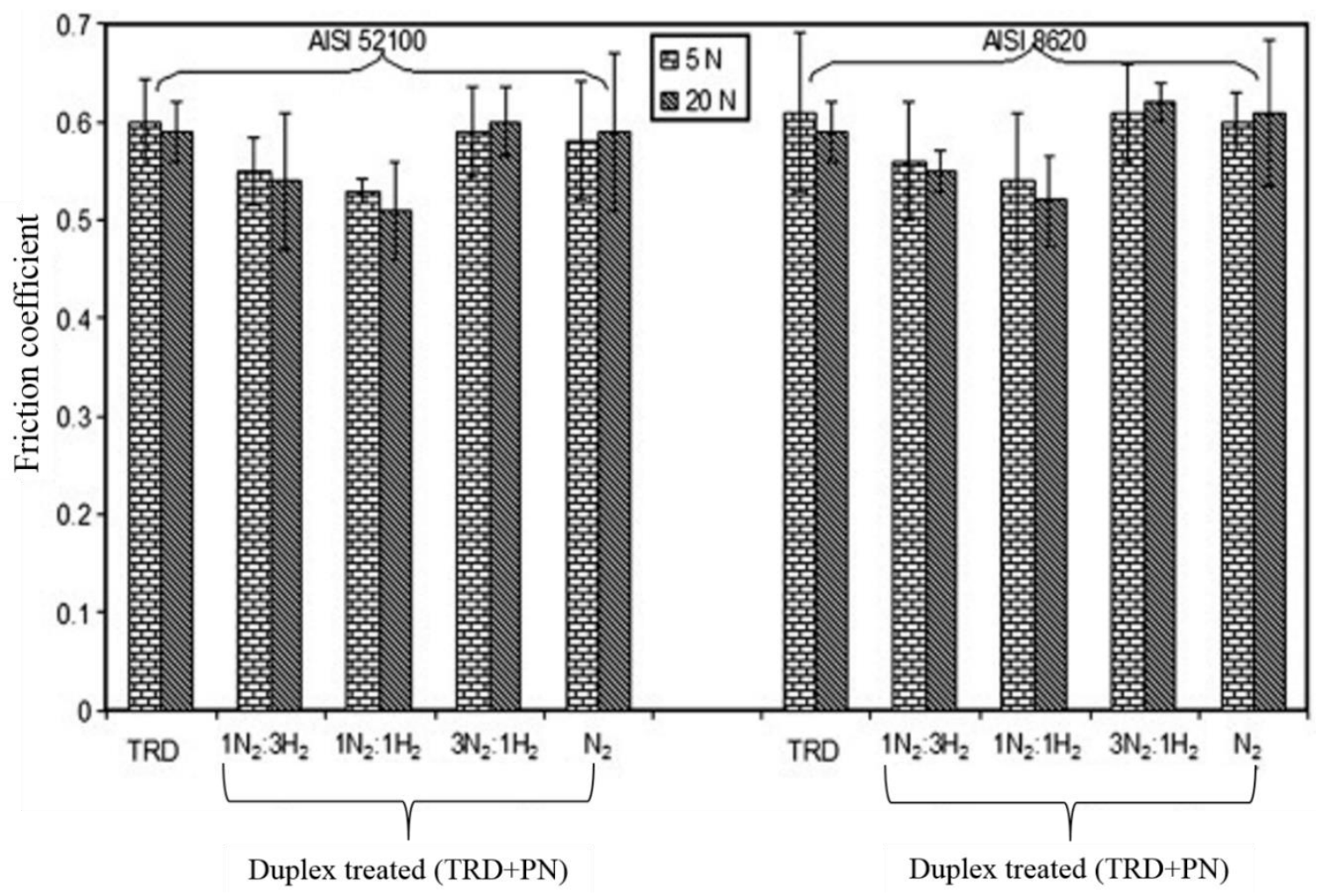

Fig. 22 Steady state friction coefficient values for AISI 52100 and 8620 steels TRD

chromized and duplex treated at various gas mixtures under loads of 5 and $20 \mathrm{~N}$ (Taktak,

Gunes et al. 2008).

Contrary to expectations, the friction coefficient of treated samples in a gas mixture of $75 \% \mathrm{~N}_{2}+25 \% \mathrm{H}_{2}$ was similar to the TRD chromized and treated in a $100 \% \mathrm{~N}_{2}$ plasma samples. Wear rate values of AISI 52100 and 8620 steels TRD chromized and duplex treated $(\mathrm{TRD}+\mathrm{PN})$ in various gas mixtures for loads of 5 and $20 \mathrm{~N}$ are shown in Fig. 23. The wear rates of samples worn with a $5 \mathrm{~N}$ load are only slightly higher than those with a load of $20 \mathrm{~N}$. Since the rate of increase in the amount of wear volume is less than the increase of applied load. The best wear resistance belongs to duplex treated samples in the gas mixture of $50 \% \mathrm{~N}_{2}+50 \% \mathrm{H}_{2}$ that is followed by steels plasma nitrided in $25 \% \mathrm{~N}_{2}+75 \% \mathrm{H}_{2}$. 
It was reported that wear rates of only chromized and duplex treated steels in a $100 \% \mathrm{~N}_{2}$ was almost similar. This can be caused by absence of chromium nitride phase formation. The wear rate of the samples duplex treated in the $50 \% \mathrm{~N}_{2}+50 \% \mathrm{H}_{2}$ plasma were reduced about $30 \%$ and $36 \%$, respectively, compared to TRD chromized ones and samples duplex treated in a $75 \% \mathrm{~N}_{2}+25 \% \mathrm{H}_{2}$ gas mixture. While the surface hardness of duplex treated samples in a gas mixture of $75 \% \mathrm{~N}_{2}+25 \% \mathrm{H}_{2}$ were higher than those of steels duplex treated in a gas mixture of $50 \% \mathrm{~N}_{2}+50 \% \mathrm{H}_{2}$. Since the outermost layer of the duplex treated samples in a gas mixture of $75 \% \mathrm{~N}_{2}+25 \% \mathrm{H}_{2}$ was hard, brittle and had poor adhesion, the most intensive wear occurred in those samples. The wear tracks of the 52100 samples chromized and duplex treated in gas mixtures of $50 \% \mathrm{~N}_{2}+50 \% \mathrm{H}_{2}$ and $75 \% \mathrm{~N}_{2}+25 \% \mathrm{H}_{2}$ using a $5 \mathrm{~N}$ load are shown in Fig. 24. Also overview of the worn surface of the WC-Co ball is demonstrated in the scanning electron micrograph. As seen in Fig. 24(a), the sliding tracks of TRD chromized sample were wider and had a relatively rougher surface with the evidence of cracking and flaking compared to that of duplex treated samples in a gas mixture of $50 \% \mathrm{~N}_{2}+50 \% \mathrm{H}_{2}$.

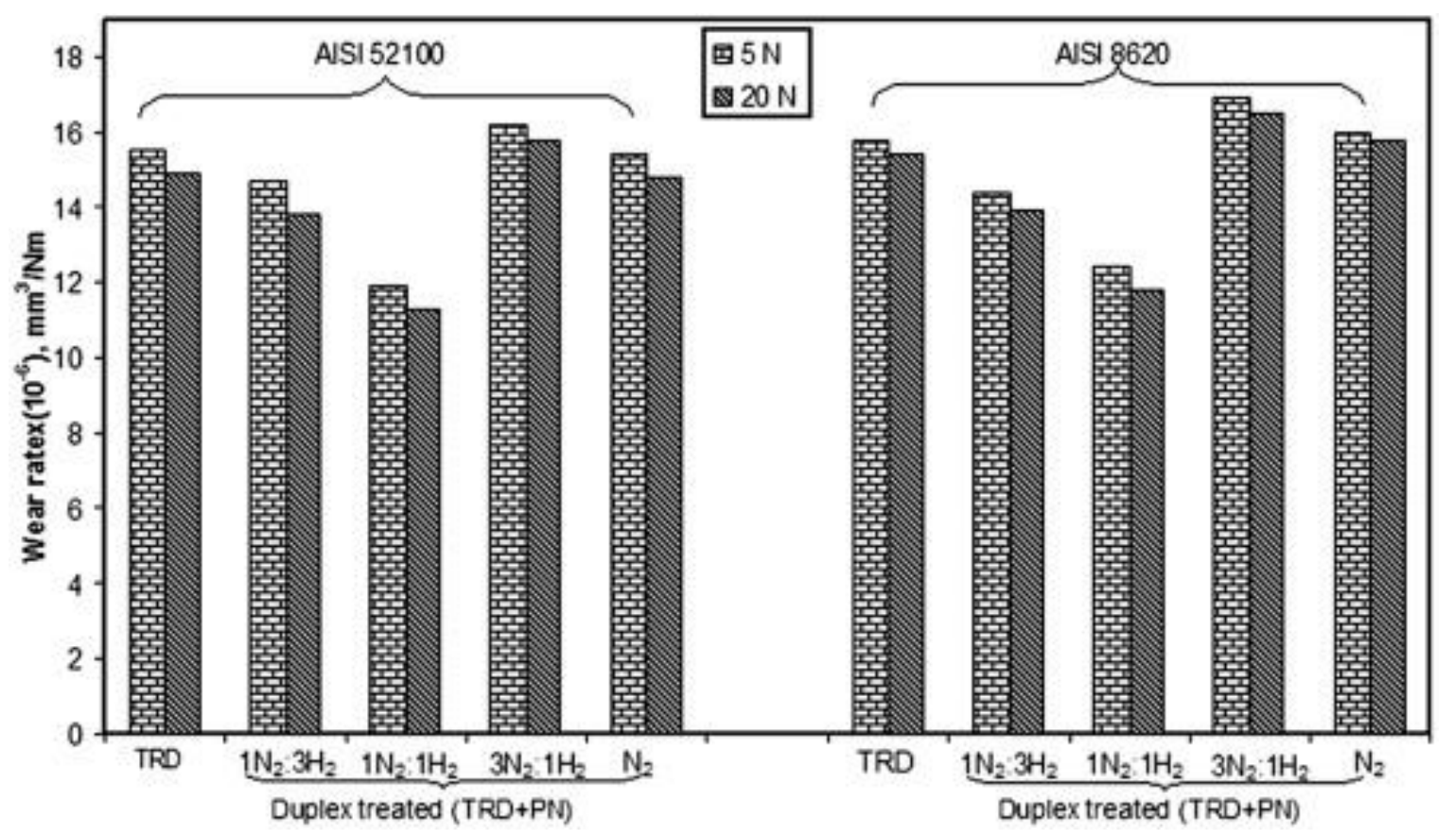

Fig. 23 Wear rate values of AISI 52100 and 8620 steels only TRD chromized and duplex treated at various gas mixtures for loads of 5 and $20 \mathrm{~N}$ (Taktak, Gunes et al. 2008).

The higher magnification micrographs of the rubbed ball contact surface against the chromized sample showed presence of wear debris besides the wear-tracked surface and revealed that the chromium carbide layer initially cracked and then broke into pieces (Fig. 24 (a) and (b)). Fig. 24(c) shows that the wear track of duplex treated samples in a gas mixture 
$50 \% \mathrm{~N}_{2}+50 \% \mathrm{H}_{2}$ was relatively shallow and smooth. Besides, no transfer of material to the ball was observed and the ball wear scar was very smooth. It was confirmed by higher magnification of the wear track (Fig. 24(d)) which showed a smooth surface and new initiation of micro-cracking. It was observed, in a gas mixture of $25 \% \mathrm{~N}_{2}+75 \% \mathrm{H}_{2}$ the sliding track of duplex treated samples had a larger surface cracking area due to the combined effects of the brittle compound layer and high stress.

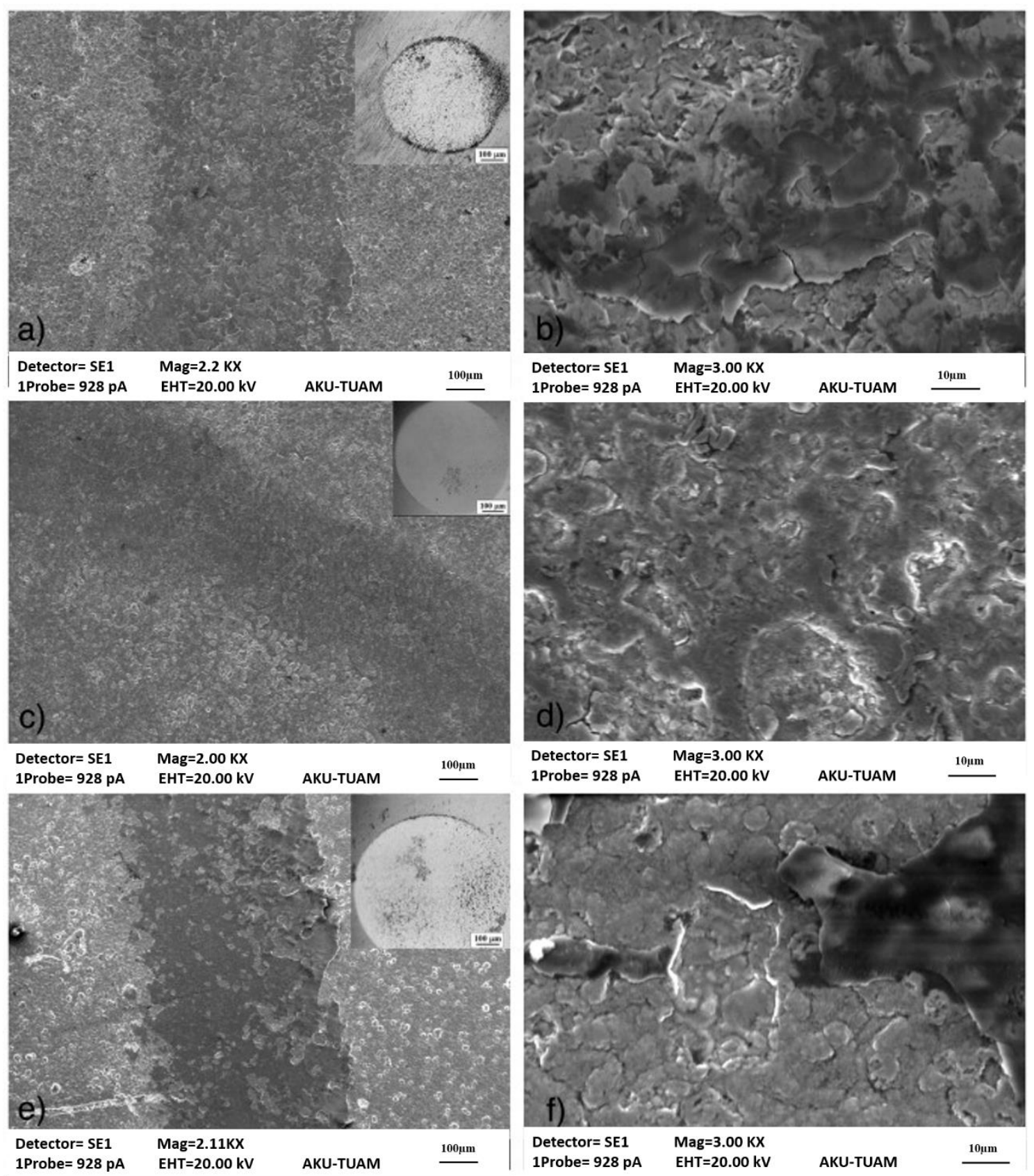

Fig. 24 SEM micrographs of the wear tracks of 52100 samples and the optical worn ball overview at the upper right corner of the micrographs for $5 \mathrm{~N}$ load; (a) wear track of only TRD chromized, (b) worn surface under high magnification of (a), (c) wear track of duplex 
treated at $50 \% \mathrm{~N}_{2}+50 \% \mathrm{H}_{2}$ plasma, d) worn surface under high magnification of (c), (e) wear track of duplex treated at $75 \% \mathrm{~N}_{2}+25 \% \mathrm{H}_{2}$ plasma, (f) worn surface under high magnification of (e)(Taktak, Gunes et al. 2008).

The contact surface of the ball is affected by the abrasive delaminated abrasive coming from the disc which is very rough and large. Delaminated area and large flake debris are shown in higher magnification of this wear track (Fig. 24(d)). The initial mechanism of wear appears to be fatigue that continues by abrasion (Taktak, Gunes et al. 2008).

In most samples, the wear rate of duplex layer is lower than the chromized layer. It could be because of formation of chromium nitride after plasma nitriding of chromized layer, which has higher hardness and improves surface wear resistance.

\section{Conclusions}

The discussion in the above sections shows that not the any two of these materials have similar compositions. For example, the percentage of $\mathrm{Cr}$ and $\mathrm{Mo}$ is very high in $\mathrm{H} 13$, the percentage of $\mathrm{Mn}$ is higher in AISI 8620 and the percentage of $\mathrm{C}$ is higher in AISI 52100 compare to others. In addition the processing conditions, such as temperature, time and gas mixture are different for different materials. Therefore the variation in properties of the treated surface is naturally expected and following conclusions can be made.

(a) The thickness of chromium nitride coatings produced by duplex surface treatment depends on the carbon content and treatment temperature. There is an optimum carbon content for which maximum thickness can be achieved. The higher thickness can also be achieved at higher temperature in chromizing process up to $1300{ }^{\circ} \mathrm{C}$.

(b) Many compounds mainly carbides and nitrides are formed by duplex treatment, such as $\mathrm{CrN}, \mathrm{Cr}_{2} \mathrm{~N}, \mathrm{Cr}_{3} \mathrm{C}_{2}, \mathrm{Cr}_{7} \mathrm{C}_{3}, \mathrm{Fe}_{2} \mathrm{~N}, \mathrm{Fe}_{3} \mathrm{~N}$, etc. XRD analysis of the duplex treated layer confirmed the formation of chromium nitride $\left(\mathrm{Cr}_{2} \mathrm{~N}\right.$ or $\left.\mathrm{CrN}\right)$ and $\mathrm{Fe}_{3} \mathrm{~N}$ phases after plasma nitriding of chromized layer. These compounds improve the surface properties of the treated work pieces. The temperature for duplex treatment affects the formation of compounds and composition of chromium and iron carbides, and iron nitrides.

(c) The hardness of the treated surface depends on the compounds formed during the duplex treatment. Micro-hardness of layers formed by duplex treatment can be as high as $2135 \pm 56$ for 52100 steel as the $\mathrm{Cr}_{3} \mathrm{C}_{2}$ dominated layers were obtained on the steels by chromizing which has higher hardness and stability compare to other chromium carbides 
$\left(\mathrm{Cr}_{7} \mathrm{C}_{3}\right.$ and $\left.\mathrm{Cr}_{23} \mathrm{C}_{6}\right)$. However, the microhardness of duplex treated layers is higher than that of chromized layers due to probably $\mathrm{Cr}_{\mathrm{x}} \mathrm{N}$ phase.

(d) The surface roughness of the treated surface decreases due to the intrinsic properties of formed phases.

(e) The high surface hardness and deep case in the duplex-treated specimen provide an excellent wear resistance. Regardless of the alloy compositions the wear tracks of the duplex-treated specimen showed an abrasive type wear while the chromized specimens showed an adhesive type wear. The plasma nitriding process reduces the friction coefficient of chromized steels due to the lower friction coefficient of chromium nitride. The friction coefficient decreases with the increase of temperature.

\section{References}

Ahangarani, S., F. Mahboubi and A. Sabour (2006). "Effects of various nitriding parameters on active screen plasma nitriding behavior of a low-alloy steel." Vacuum 80(9): 1032-1037.

Arai, T. and S. Harper (1991). "Thermoreactive deposition/diffusion process." ASM International, ASM Handbook. 4: 448-453.

Baggio-Scheid, V., G. De Vasconcelos, M. Oliveira and B. Ferreira (2003). "Duplex surface treatment of chromium pack diffusion and plasma nitriding of mild steel." Surface and Coatings Technology 163: 313-317.

Bell, T., H. Dong and Y. Sun (1998). "Realising the potential of duplex surface engineering." Tribology International 31(1-3): 127-137.

Bull, S. and D. Rickerby (1990). "Compositional, microstructural and morphological effects on the mechanical and tribological properties of chromium nitrogen films." Surface and Coatings Technology 43: 732-744.

Cao, H., C. Wu and J. Liu (2007). "A Novel Duplex Low-temperature Chromizing Process at $500{ }^{\circ} \mathrm{C} . "$ Material Science and Technology 23: 823-827.

Chang, D. Y., S. Y. Lee and S.-S. Kang (1999). "Effect of plasma nitriding on the surface properties of the chromium diffusion coating layer in iron-base alloys." Surface and Coatings Technology 116: 391-397.

De Las Heras, E., D. A. Egidi, P. Corengia, D. González-Santamaría, A. García-Luis, M. Brizuela, G. A. López and M. F. Martinez (2008). "Duplex surface treatment of an AISI 316L stainless steel; microstructure and tribological behaviour." Surface and Coatings Technology 202(13): 2945-2954.

Figueroa, C. A. and F. Alvarez (2006). "On the hydrogen etching mechanism in plasma nitriding of metals." Applied Surface Science 253(4): 1806-1809.

Haftlang, F., A. Habibolahzadeh and M. Heydarzadeh Sohi (2014). "Duplex treatment of AISI 1045 steel by plasma nitriding and aluminizing." Vacuum 107(0): 155-158.

Hakami, F., M. H. Sohi and J. R. Ghani (2011). "Duplex surface treatment of AISI 1045 steel via plasma nitriding of chromized layer." Thin Solid Films 519(20): 6792-6796.

Hakami, F., M. H. Sohi, J. R. Ghani and M. Ebrahimi (2011). "Chromizing of plasma nitrided AISI 1045 steel." Thin Solid Films 519(20): 6783-6786.

Heydarzadeh Sohi, M., Ebrahimi, M., Honarbakhsh Raouf, A., Mahboubi, F. (2010). "Comparative study of the corrosion behaviour of plasma nitrocarburised AISI 4140 steel before and after post-oxidation." Material Design 31: 4432-4437. 
Hubbard, P., J. Partridge, E. Doyle, D. McCulloch, M. Taylor and S. Dowey (2010). "Investigation of nitrogen mass transfer within an industrial plasma nitriding system I: The role of surface deposits." Surface and Coatings Technology 204(8): 1145-1150.

Hurkmans, T., D. B. Lewis, J. S. Brooks and W. D. Münz (1996). "Chromium nitride coatings grown by unbalanced magnetron (UBM) and combined arc/unbalanced magnetron (ABS ${ }^{\mathrm{TM}}$ ) deposition techniques." Surface and Coatings Technology 86-87, Part 1(0): 192199.

Lee, J.-W. and J.-G. Duh (2004). "Evaluation of microstructures and mechanical properties of chromized steels with different carbon contents." Surface and Coatings Technology 177: 525531.

Lee, S. Y., J. W. Chung, K. B. Kim, J. G. Han and S. S. Kim (1996). "Duplex plasma surface treatment process on mild steel and high alloyed tool steel." Surface and Coatings Technology 86-87, Part 1(0): 325-331.

Lee, S. Y., G. S. Kim and B.-S. Kim (2004). "Mechanical properties of duplex layer formed on AISI 403 stainless steel by chromizing and boronizing treatment." Surface and Coatings Technology 177-178(0): 178-184.

Ma, S., Y. Li and K. Xu (2001). "The composite of nitrided steel of H13 and TiN coatings by plasma duplex treatment and the effect of pre-nitriding." Surface and Coatings Technology 137(2-3): 116-121.

Mahboubi, F. and M. Fattah (2005). "Duplex treatment of plasma nitriding and plasma oxidation of plain carbon steel." Vacuum 79(1-2): 1-6.

Mouri, L., I. Mabille, C. Fiaud, J. Amouroux, G. Catillon and R. Gras (2001). "Study of corrosion resistance and surface properties of carbon steel after a duplex plasma treatment." Thin Solid Films 389(1-2): 153-160.

Novák, P., D. Vojtěch, J. Šerák, V. Knotek and B. Bártová (2006). "Duplex surface treatment of the Nb-alloyed PM tool steel." Surface and Coatings Technology 201(6): 3342-3349.

Ozdemir, O., S. Sen and U. Sen (2007). "Formation of chromium nitride layers on AISI 1010 steel by nitro-chromizing treatment." Vacuum 81(5): 567-570.

Panjan, P., I. Urankar, B. Navinšek, M. Terčelj, R. Turk, M. Čekada and V. Leskovšek (2002). "Improvement of hot forging tools with duplex treatment." Surface and Coatings Technology 151-152(0): 505-509.

Pogrebnjak, A. D. and N. I. Shumakova (1999). "Effect of 'duplex' treatment on changes of physical and mechanical properties of steel $(0.3 \mathrm{wt} \% \mathrm{C})$." Surface and Coatings Technology 122(2-3): 183-187.

Pramanik, A., L. C. Zhang and J. A. Arsecularatne (2007). "Micro-Indentation of Metal Matrix Composite - An FEM Analysis." Key Engineering Materials 340-341: 563-570.

Pramanik, A., L. C. Zhang and J. A. Arsecularatne (2008). "Deformation mechanisms of MMCs under indentation." Composites Science and Technology 68(6): 1304-1312.

Qi, F., Y. X. Leng, N. Huang, B. Bai and P. C. Zhang (2007). "Surface modification of 174PH stainless steel by DC plasma nitriding and titanium nitride film duplex treatment." Nuclear Instruments and Methods in Physics Research Section B: Beam Interactions with Materials and Atoms 257(1-2): 416-419.

Shetty, K., S. Kumar and P. Raghothama Rao (2009). "Effect of ion nitriding on the microstructure and properties of Maraging steel (250 Grade)." Surface and Coatings Technology 203(10): 1530-1536.

Taktak, S., I. Gunes, S. Ulker and Y. Yalcin (2008). "Effect of $\mathrm{N}_{2}+\mathrm{H}_{2}$ gas mixtures in plasma nitriding on tribological properties of duplex surface treated steels." Materials Characterization 59(12): 1784-1791.

Taktak, S., S. Ulker and I. Gunes (2008). "High temperature wear and friction properties of duplex surface treated bearing steels." Surface and Coatings Technology 202(14): 3367-3377. 
Tamaki, M., Y. Tomii and N. Yamamoto (2000). "The role of hydrogen in plasma nitriding: Hydrogen behavior in the titanium nitride layer." Plasmas \& Ions 3(1-4): 33-39.

Van Stappen, M., M. Kerkhofs, C. Quaeyhaegens and L. Stals (1993). "Introduction in industry of a duplex treatment consisting of plasma nitriding and PVD deposition of TiN." Surface and Coatings Technology 62(1): 655-661.

Wang, D.-Y., K.-W. Weng, C.-L. Chang and W.-Y. Ho (1999). "Synthesis of $\mathrm{Cr}_{3} \mathrm{C}_{2}$ coatings for tribological applications." Surface and Coatings Technology 120: 622-628.

Wang, Z. B., J. Lu and K. Lu (2005). "Chromizing behaviors of a low carbon steel processed by means of surface mechanical attrition treatment." Acta Materialia 53(7): 2081-2089.

Wei, C.-Y. and F.-S. Chen (2005). "Characterization on multi-layer fabricated by TRD and plasma nitriding." Materials Chemistry and Physics 90(1): 178-184.

Yang, Q., T. Senda, N. Kotani and A. Hirose (2004). "Sliding wear behavior and tribofilm formation of ceramics at high temperatures." Surface and Coatings Technology 184(2-3): 270-277.

Zagonel, L., C. Figueroa, R. Droppa Jr and F. Alvarez (2006). "Influence of the process temperature on the steel microstructure and hardening in pulsed plasma nitriding." Surface and Coatings Technology 201(1): 452-457.

Zeng, D., S. Yang and Z. D. Xiang (2012). "Formation of hard surface layer on austenitic stainless steels via simultaneous chromising and nitriding by pack cementation process." Applied Surface Science 258(12): 5175-5178.

Zlatanović, M. (2003). "Combined plasma surface treatments for wear and corrosion protection." Tribology in Industry 25(3-4): 65-70. 